\title{
Impact of physical modifications on starch nutritional fractions: rapidly digestible starch, slowly digestible starch and resistant starch
}

\begin{abstract}
E.R.J. Samarakoon
Department of Food Science and Technology, Faculty of Agriculture, University of Peradeniya, Sri Lanka. Tel: +94701324096, E-mail: rasanjalis@agri.pdn.ac.lk

DOI: $10.31665 /$ JFB.2020.12249

Received: December 22, 2020; Revised received \& accepted: December 29, 2020

Citation: Samarakoon, E.R.J. (2020). Impact of physical modifications on starch nutritional fractions: rapidly digestible starch, slowly digestible starch and resistant starch. J. Food Bioact. 12: 106-121.

Abstract

The industrial utilization of native starches is limited because of their poor qualities and different starch modifications are used to improve functionality of starch. Physical modification of starch is preferred since it is simple, inexpensive, and specially it does not involve any chemical reagents. Physical modifications can be divided into thermal and non-thermal treatments. These techniques alter physicochemical properties of starch including in vitro digestibility, which indicates the nutritional value of starch. Starch nutritional fractions are of three types; RDS (rapidly digestible starch), SDS (slowly digestible starch) and RS (resistant starch). It is important to understand how physical modifications affect starch nutritional fractions as both SDS and RS have beneficial health effects and specially RS has the potential to be used as a natural bioactive compound. This review aims to summarize the recent knowledge regarding the physical modifications and their impact on in vitro digestibility and nutritional fractions of starch.
\end{abstract}

Keywords: Physical modification; Starch digestibility; RDS; SDS; RS.

\section{Introduction}

Starch provides $50-70 \%$ of the energy requirement in the human diet, serving as a direct source of glucose. Starch has a great potential to serve as an important material for both food and nonfood industries (Srikaeo, 2016). The industrial utilization of native starch is limited due to its inherent imperfect nature, such as water insolubility, low stability at low $\mathrm{pH}$, high temperature, and tendency to easily retrograde and undergo syneresis forming unstable pastes and gels (Ashogbon, 2018; Punia, 2020). Therefore, native starches are often modified using different techniques to enhance their functional properties relevant to industrial applications (Wang et al., 2020). The physical modification is preferred in the food industry because it does not require any chemical treatment, hence it is safe (Zhang et al., 2019). Physical modification techniques can be categorized into thermal and non-thermal treatments. Thermal treatments include extrusion, heat moisture treat- ment, annealing and microwave heating. Meanwhile, non-thermal treatments include ultrasound and high-hydrostatic pressure treatments (Ashogbon, 2018).

Starch is the main carbohydrate in human nutrition and the digestion of starch is not a simple and single process. The major physiological properties of starch are the release of glucose as a source of energy for the body and the timeline of digestion (Lehman and Robin, 2007). Starch digestibility is one of the important properties that can be altered due to physical modifications. The enzymatic digestion of starch often involves a combination of one or more endo-enzymes and exo-enzymes that convert the products of endo-enzymes into monomer units or act directly (Zhang et al., 2013). Enzyme hydrolysis of granular starch is a heterogeneous reaction, which involves a reaction between an enzyme in a solution and a solid substrate represented by the granules (Tahir et al., 2010). The steps involved in enzyme digestion include diffusion of enzymes onto the granule surface, followed by adsorption and subsequent catalytic events (Uthumporn et al., 2010). According to 
in vitro measurement of starch digestibility, starch can be divided into three groups, namely rapidly digestible starch (RDS), slowly digestible starch (SDS) and resistant starch (RS) (Englyst et al., 1999). SDS and RS have gained attention in many researchers as they play important roles in human health. SDS may help to control and prevent hyperglycaemic-related diseases while RS may be helpful in maintaining colon health (Miao et al., 2015). RS is considered as a component of dietary fibre and it has the potential to be a source of prebiotic compound, hence the food industry and researchers are showing interest on RS as a natural bioactive ingredient (Amini et al., 2016). The present review focuses on the impact of different physical modification techniques on starch digestibility and the content of RDS, SDS and RS from different botanical origins.

\section{Starch nutritional fractions}

Starch and starch-containing foods can be classified according to their digestibility, which is generally characterized by the rate and the duration of the glycemic response (Singh et al., 2010). Among the starch nutritional fractions, RDS is the fraction of starch granule that causes a rapid increase in blood glucose concentration after ingestion of starch, whereas SDS is the fraction of starch that is digested slowly but completely in the human small intestine (Dona et al., 2010). RS is the sum of the starch and products of starch degradation not absorbed in the small intestine of healthy individuals (Englyst et al., 1999). RDS is measured chemically as the starch that is converted to the constituent glucose molecules in $20 \mathrm{~min}$ utes of enzyme digestion whereas; SDS is defined as the starch that is digested between 20 and 120 min under standard conditions of substrate and enzyme concentration. RS is measured by subtracting the amount of glucose released within $120 \mathrm{~min}$ of in vitro digestion from total starch (TS) (Englyst et al., 1999). The AACC method is also used to determine starch nutritional fractions. This method is in many ways similar to Englyst method. However, hydrolysis is carried out for 16 hours and RDS is measured as the starch that is digested within 30 minutes of digestion, SDS is the starch that is digested between 30 minutes to 16 hours and RS is measured by subtracting the amount of glucose released within $120 \mathrm{~min}$ of in vitro digestion from total starch (Ambigaipalan et al., 2014; Perera et al., 2010).

RDS is mainly comprised of amorphous and dispersed starch and is found in large amounts in starchy foods cooked by moist heat, such as bread and potatoes (Sajilata et al., 2006). RDS content of cereal starches $(2.5-90 \%)$ is higher than tuber $(0.1-21.0 \%)$ and legume (3.0-21.0\%) starches. The shortest A chains (DP 5-10) cannot form double helices, and they may disrupt the ordered crystalline structure leading to crystalline defects. Therefore, starches with high amount of shortest A chains are likely to be easily attacked by enzymes leading to higher amount of RDS (Zhang et al., 2006b).

SDS consists of physically inaccessible amorphous starch and raw starch with A- and C-type crystalline structures, while B-type starch is resistant to enzyme hydrolysis (Lee and Moon, 2015). SDS has physical structures that decrease enzyme accessibility and chemical structures that limit the rate of enzyme action (Zhang and Hamaker, 2009). Presence of channels in cereal starches enable migration of enzymes into the center of granule and initiate hydrolysis leading to layer-by-layer inside-out pattern where amorphous and crystalline regions are digested simultaneously and this sideby-side digestion mechanism of native cereal starches cause slow digestion and produce more SDS ( $>50 \%$ ) (Zhang et al., 2006a).
Cereal starches which had higher short chains $(A+B 1)$ showed a higher proportion of SDS compared to potato starch which had less short chains, suggesting that SDS is associated with the fraction of short chains in amylopectin which contributes to the formation of double helices and crystalline lamellae in the crystalline region, and hence, crystalline region is the major determining factor for the slow digestion properties of native cereal starches (Zhang et al., 2006b).

RS is the fraction of starch that cannot be digested in the small intestine, and may be subject to bacterial fermentation in the large intestine to produce short-chain fatty acids and other products (Bello-Perez et al., 2020). RS positively influences the functioning of the digestive tract, microbial flora, blood cholesterol level, glycemic index and assists in the control of diabetes. RS has been shown to have lower impact on the sensory properties of food as a dietary fibre source compared with traditional sources of fibre, as whole grains, fruits or bran (Fuentes-Zaragoza et al., 2010). RS contents of cereal and pulse starches vary with the amylose and amylopectin contents and their chain lengths (Perera et al., 2010). RS fractions have extremely broad and diverse range and different types ranging from RS1 to RS5. At present, these are mostly defined according to physical and chemical characteristics (Nugent, 2005).

RS1 is entrapped within whole or partly milled grains or seeds and physically inaccessible (Niba, 2002). RS2 is raw starch granules (such as banana and potato) and high-amylose (high-amylose corn) starches which are protected from enzyme digestion by the conformation or structure of the starch granule. This compact structure restricts the accessibility of digestive enzymes, and accounts for the resistant nature of RS2 (Fuentes-Zaragoza et al., 2010). RS3 are retrograded starches, which may be formed during cooling of cooked foods (Jiang et al., 2020). Foods which are processed with heat and moisture, therefore, contain some RS3 (Sajilata, et al., 2006). RS3 is thermally stable and this property allows it to be stable in most normal cooking operations, enabling its use as a potential ingredient in a wide variety of conventional foods (Ma et al., 2020). RS4 is formed using chemical modifications, such as substitution, conversion, or cross linking, which can prevent starch digestion by blocking enzyme access and forming linkages other than $\alpha$-D-( $1 \rightarrow 4)$ and $\alpha-D-(1 \rightarrow 6)$ (Coulon et al., 2020; FuentesZaragoza et al., 2010; Sajilata et al., 2006). Amylose-lipid complex has been proposed as RS5, as a result its resistance to enzyme hydrolysis (DeMartino and Cockburn, 2020). The enzyme resistance of amylose-lipid complex depends on the molecular structure of the lipid and the crystalline structure of the single helices (Hasjim et al., 2013).

\section{Health benefits of resistant starch}

Many studies have shown that the RS starch has many health benefits and since it is a part of dietary fiber, RS has the functionality of dietary fiber as well (Fuentes-Zaragoza et al., 2010; Jiang et al., 2020). RS provides a source of energy for microbial growth in human colon and short chain fatty acids (SCFAs) which produce as a result of bacterial fermentation of RS help to maintain low $\mathrm{pH}$ in the gut leading to the inhibition of the action of pathogenic bacteria (Jiang et al., 2020). Guo et al. (2020) have performed a systemic review on the impact of dietary intake of RS on obesity and related health condition and suggested that the there is no direct effect of dietary intake of RS on body weight or body composition, but there are beneficial effects on blood glucose homeostasis, insulin sensitivity, and gut hormone concentration. The bacterial fermen- 
Table 1. Health benefits of resistant starch

\begin{tabular}{ll}
\hline Health condition/disease & Effect of resistant starch \\
\hline Colorectal cancer & Reduce gut $\mathrm{pH}$ which creates an environment less prone to the formation of cancerous tumors \\
Diabetes & $\begin{array}{l}\text { Decrease postprandial insulin and glucose responses, increase insulin sensitivity, and delay onset of insulin } \\
\text { resistance }\end{array}$ \\
Obesity & Low caloric value and reduced energy intake, increased satiety \\
Blood lipids levels & Inhibit the synthesis of cholesterol and fatty acids in the liver \\
Mineral absorption & Facilitate absorption of calcium and magnesium by SCFs \\
Diarrhea & Shorten the duration of rotavirus diarrhea by probiotics \\
\hline
\end{tabular}

Sources: Amini et al., 2016; Guo et al., 2020; Jiang et al., 2020.

tation of RS may play an important role with respect to prevention of colorectal cancer as both in vitro and in vivo studies have reported that butyrate production from starch is high and butyrate has been suggested to have a protective effect on colorectal cancer (Amini et al., 2016). The slow digestion RS has positive impact on controlling diabetes as it reduces postprandial glucose and insulin responses (Sajilata et al., 2006). In vivo studies have shown that RS rich diets reduced plasma cholesterol and triglyceride levels indicating the positive effects of RS starch on lipid metabolism (Fuentes-Zaragoza et al., 2010). However, the impact of RS on physiological/health conditions may vary depending on the structural variations of the RS and the differences in individual microbiota composition (DeMartino and Cockburn, 2020). The effects on RS on health conditions are presented in Table 1.

\section{Thermal modifications of starch}

\subsection{Extrusion}

Extrusion cooking is one of the industrial processes used to produce pregelatinized starch. The major functional property of pregelatinized starch is increased water absorption and water solubility upon dispersion in cold water. Extrusion cooking is more versatile compared to other techniques used to prepare pregelatinized starches such as drum drying and spray drying, which explains its popularity (Ashogbon and Akintayo, 2014; Colonna et al., 1984). Extrusion is a high-temperature, short-time process in which flours or starches are plasticised and cooked in a barrel under one or more varieties of conditions of moisture, pressure, temperature and mechanical shear, causing molecular transformation and chemical reactions (Adeleye et al., 2020; Riaz, 2000; Singh et al., 2007). Most of the commercially available extruders allow temperature control of the barrel and preferred levels of thermal energy input can be applied (Wolf, 2010). High shear extruders disrupt starch granule structure and are used to produce pregelatinized starch (Riaz, 2000). Several chemical and/or physicochemical changes can occur during extrusion: cleavage, binding of smaller molecules, loss of native structure, recombination of fragments and thermal degradation (Arora et al., 2020). In extrusion, gelatinization occurs at a lower moisture content in extrusion (12-22\%), which makes it different from other food processing techniques (Camire, 2000). Extrusion converts starch from a granular and semi-crystalline material into a highly viscous, plastic material which causes a reduction in molecular weight (Colonna et al., 1984) and crystallinity (Sharma et al., 2015).

The information on the impact of extrusion on in-vitro hydroly- sis and RS content of starches are conflicting. Screw speed, temperature and moisture content could affect the RS formation in the extruder (Agustiniano-Osornio et al, 2005) as well as the enzyme concentration, enzyme purity, and time of hydrolysis. Extrusion has been shown to increase susceptibility towards enzyme hydrolysis and decrease RS content in normal corn (Yan et al., 2019), Gelose 50 (Shrestha et al., 2015), Hylon VII (Htoon et al.,2009) and Gelose 80 starches (Chanvrier et al., 2007; Htoon et al., 2009; Shrestha et al., 2010, 2015). Starch granules are disrupted by thermal and mechanical energy during extrusion cooking which would be expected to increase accessibility of amylases to starch polymers. However, upon cooling, hydrated amylose (and amylopectin) chains may undergo a process of retrogradation, and may consequently acquire resistance to enzymatic digestion (Htoon et al., 2009).

Extrusion has been shown to decrease susceptibility towards enzyme hydrolysis of normal maize starch (Sharma et al., 2015; Shrestha et al., 2015). However, Chanvrier et al. (2007) reported a slight increase in enzyme resistant starch (ERS) in normal maize starch (from 1.5 to $2.1 \%$ ) after extrusion. Shrestha et al. (2015) observed that increase in susceptibility towards enzyme hydrolysis after extrusion was less in high amylose maize starch compared to normal maize starch. This difference could be attributed to greater tendency of normal maize starch to undergo gelatinization under the extrusion conditions whereas high amylose starches may not undergo complete gelatinization, due to their relatively extended phase transition and the presence of limiting water during extrusion which further raised the phase transition temperature (Shrestha et al., 2015). The susceptibility of extruded rice starch to hydrolysis by pancreatic $\alpha$-amylase and amyloglucosidase has been shown to increase as the feed moisture content increases (from 30 to $50 \%$ ), indicating that increased degree of gelatinization upon extrusion facilitates the access of the enzymes to the starch molecules (Ye et al., 2018).

ERS content was slightly increased in wheat (from 0.8 to $2.8 \%$ ) starch after extrusion (Chanvrier et al., 2007). An increase in RS content on extrusion has also been observed in mango starch ( $28.7 \%$ amylose) processed under different temperature, moisture and screw speed conditions and a maximum of $97.0 \pm 0.01 \mathrm{~g} / \mathrm{kg} \mathrm{RS}$ content was obtained compared to the low value of $11 \pm 0.3 \mathrm{~g} / \mathrm{kg}$ for native starch (Agustiniano-Osornio et al., 2005).

Legume starches such as faba bean (Alonso et al., 2000), kidney bean (Alonso et al., 2000; Sharma et al., 2015) and field pea (Sharma et al., 2015) have been shown to exhibit increased susceptibility towards enzyme hydrolysis after extrusion. A decrease in SDS (from 17.8 to $8.7 \%$ in kidney bean, from 25.9 to $11.9 \%$ in field pea) and RS (from 70.1 to $15.9 \%$ in kidney bean, from 60.1 to $14.8 \%$ in field pea) contents and an increase in RDS (from 10.4 
to $75.3 \%$ in kidney bean, from 12.9 to $72.2 \%$ in field pea) contents were observed in kidney bean and field pea starches (Sharma et al., 2015). Extrusion increased the enzyme digestibility of African yam beans, bambara groundnut, and pigeon pea starches and increase of extrusion temperature (from 100 to $140{ }^{\circ} \mathrm{C}$ ) caused further increase in the digestibility where RDS fractions were significantly increased (Adeleye et al., 2020). Increase in RDS contents after extrusion could be due to loss of structural integrity of granules as a result of increased shearing and kneading in the extruder barrel (Sharma et al., 2015).

Variation of RS content with varying extrudate moisture content has been studied. Increasing extrudate moisture content from 20.8 to $36.3 \%$ caused aslight increase in ERS content from 13.1 to $15.6 \%$ in Gelose 80 (Shrestha et al., 2010). RS content of kidney bean starch remained unchanged while RS content slightly increases in normal maize (from 1.6 to $2.5 \%$ ) and field pea (from 14.8 to $15.6 \%$ ) starches when extrudate moisture content increase from 20 to $24 \%$ (Sharma et al., 2015). Shrestha et al. (2010) postulated that increase in moisture content under high temperatureand shearing facilitates gelatinization of starch and this gelatinized starch is more likely to retrograde and contribute towards ERS. However, it is difficult to correlate extrudate moisture content and RS content, because RS content varies depending on materials/machine interactions caused by the different rheology of different starches, and the extent of structure loss (Sharma et al., 2015).

RS3 corresponds to the resistant fractions in starch-based foods that have been processed, cooled and stored. Extruded starches have been stored and analyzed for RS content to determine the influence of storage conditions on the formation of RS. Chanvrier et al. (2007) stored extruded waxy, normal, high amylose maize and wheat starch at 4,30 and $60^{\circ} \mathrm{C}$ for 72 hours and found that ERS content did not change significantly except for high amylose starch, which showed an ERS content of $27.3 \%$ after conditioning at $60{ }^{\circ} \mathrm{C}$, compared to the $20 \%$ ERS content obtained for extruded starch. Storage of extruded Gelose 80 at $4{ }^{\circ} \mathrm{C}$ for 12 days also showed a slight increase in ERS (from 13.1 to $15.6 \%$ ) content (Shrestha et al., 2010).

High amylose starches contain a significant RS content compared to starches with lower amylose content even after extrusion and this offers the possibility of formulating foods realistically achieving high level of RS content (Shrestha et al., 2010) and also storage of extruded high amylose starches prior to digestion could further increase the RS content (Chanvrier et al., 2007).

\subsection{Annealing}

Annealing (ANN) is a hydrothermal treatment that modifies physicochemical properties of starch without destroying the granular integrity. Annealing of starch granules occurs in excess $(>60 \%$ $\mathrm{w} / \mathrm{w})$ or intermediate $(40-55 \%, \mathrm{w} / \mathrm{w})$ moisture content and at a temperature above the glass transition temperature $\left(\mathrm{T}_{\mathrm{g}}\right)$ but below the onset temperature of gelatinization $\left(\mathrm{T}_{\mathrm{o}}\right)$ for a certain time period (Ashogbon and Akintayo, 2014; BeMiller and Huber, 2015; Jacobs and Delcour 1998; Jayakody and Hoover 2008; Zavareze and Dias 2011). Annealing causes crystalline perfection in starch granules and facilitates interactions between starch chains which lead to changes in physicochemical properties. The extent of crystalline perfection and starch chain interactions occur during annealing varies depending on the starch source and annealing conditions. Annealing temperature, moisture content, and time vary widely with the botanical origin. Single step annealing has been used in many studies while double and multi-step annealing have been conducted to a limited extent (Jayakody and Hoover, 2008).
Different starch to water ratios have been used in annealing studies at varying temperatures. Generally, excess moisture content and a temperature $5-15{ }^{\circ} \mathrm{C}$ below onset temperature of gelatinization are the annealing conditions which give significant changes to a given starch (Jayakody and Hoover, 2008). Annealing causes several changes to starch structure and properties such as increase in granular stability, crystalline growth and perfection, increase in the interactions between starch chains in the amorphous and crystalline regions of the granule, increase in crystallinity, increase in gelatinization temperatures and a narrowing of the gelatinization temperature range, and reduction in granular swelling and amylose leaching (Hoover and Vasanthan, 1994; Lan et al., 2008; Waduge et al., 2006; Zhong et al., 2020). However, the occurrence and extent of these changes depend on the starch source and annealing conditions.

Although there is a wide range of literature describing susceptibility of annealed starches towards enzyme hydrolysis, reported data are conflicting which could be due to differences in annealing conditions, analysis methods and starch source (BeMiller and Huber, 2015; Jayakody and Hoover, 2008). In cereal starches, annealing has been shown to increase susceptibility of normal corn (Chung et al., 2009a, 2009b; Rocha et al., 2012; O'Brien and Wang, 2008), waxy rice (Zeng et al., 2015), low-, medium-, and highamylose rice (Dias et al., 2010), Hylon V and Hylon VII (O'Brien and Wang, 2008), waxy wheat (Lan et al., 2008), oat (Hoover and Vasanthan, 1994), waxy corn and waxy barley (Samarakoon et al., 2020) and decreased susceptibility of waxy, normal and high amylose rice (Hung et al., 2016), wheat (Su et al., 2020; Lan et al., 2008; Hoover and Vasanthan, 1994), waxy potato (Samarakoon et al., 2020), mung bean starches (Zou et al., 2019) towards enzyme hydrolysis. However, annealed waxy corn (O'Brien and Wang, 2008; Rocha et al., 2012; Wang et al., 2014), normal and high amylose corn (Wang et al., 2014) starches exhibited no change in susceptibility towards enzyme hydrolysis compared to native starches. It is difficult to develop a relationship between amylose content and digestibility since there are other factors affecting enzyme digestibility. Dias et al. (2010) found that the increase in the percentage of hydrolysis of low-, medium-, and high-amylose rice starches was more intense as the annealing temperature increased from $45-60{ }^{\circ} \mathrm{C}$.

Legume starches such as field pea (Chung et al., 2009b, 2010; Wang et al., 2013), lentil (Chung et al., 2009b, 2010), and navy bean (Chung et al., 2010) starches have been shown to exhibit increased susceptibility towards enzyme hydrolysis on annealing whereas, black bean, pinto bean (Simsek et al., 2012) and lentil (Hoover and Vasanthan, 1994) starches have been shown to exhibit decreased susceptibility towards enzyme hydrolysis upon annealing. O'Brien and Wang (2008) reported that the susceptibility of annealed potato starch towards bacterial $\alpha$-amylase as well as amyloglucosidase was higher than its native counterpart whereas, annealing has been shown to reduce susceptibity of potato starch towards porcine pancreas $\alpha$-amylase (Hoover and Vasanthan, 1994) and prancreatin (a mixture of $\alpha$-amylase from porcine pancreatic stomach mucosa, lipase and protease) (Jacobs et al., 1998). However, Rocha et al. (2011) reported that annealing did not change the susceptibility of potato starch towards bacterial $\alpha$-amylase and amyloglucosidase. Jyothi et al. (2011) reported that susceptibility of sweet potato starch towards porcine pancreas $\alpha$-amylase decreased upon annealing while Song et al. (2014) found that susceptibility of sweet potato starch towards pancreatin and amyloglucosidase increased on annealing. Cassava starch has shown a decrease in susceptibility towards porcine pancreas $\alpha$-amylase (Jyothi et al., 2011 ) but an increase in susceptibility towards bacterial $\alpha$-amylase and amyloglucosidase (Rocha et al., 2011) on annealing. These re- 


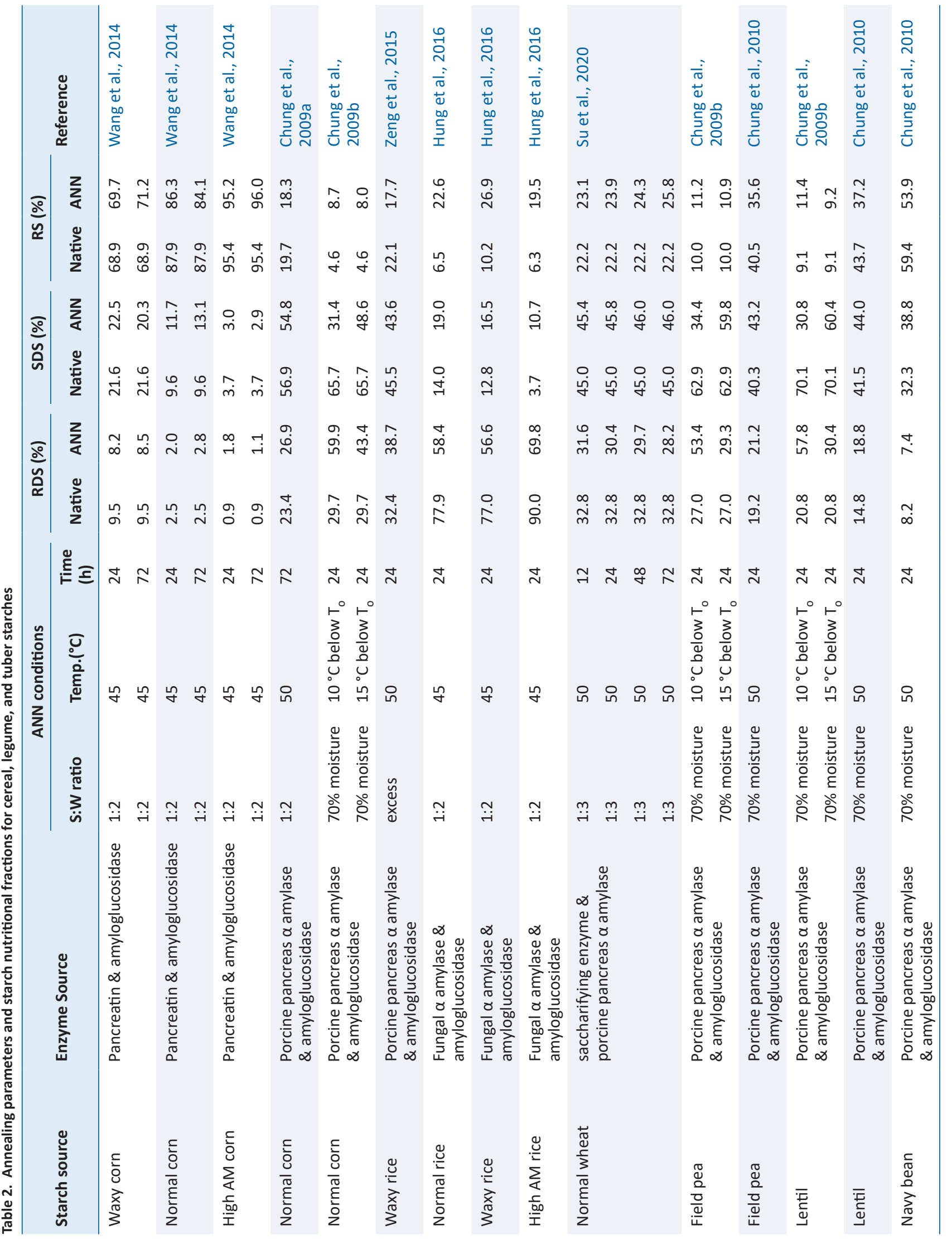




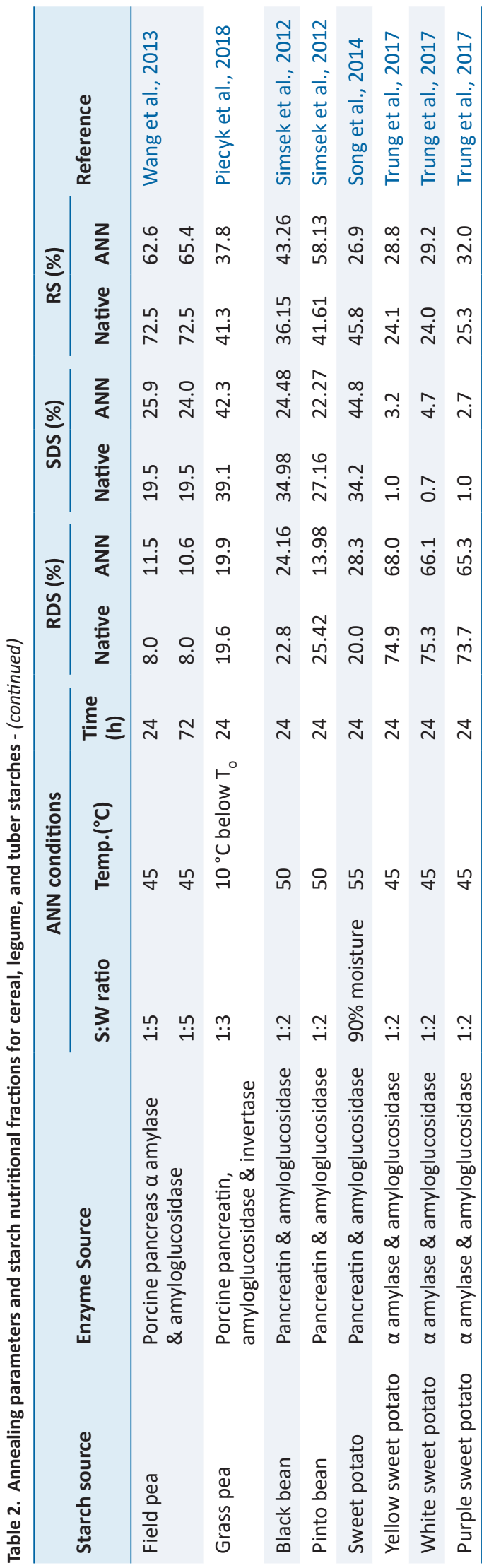

sults clearly show that even the same starch can behave differently towards different enzymes and these differences can further vary greatly depending on the annealing conditions (Table 2).

With regards to nutritional fractions of starches RDS, SDS and RS contents, only slight changes were observed in RDS and RS contents while SDS content increased in normal corn starch on annealing. Increase in SDS content was attributed to slight disruption of crystalline lamellae or small dissociation of double helices (Wang et al., 2014). However, Chung et al. (2009b) reported an increase in RDS and RS contents and a decrease in SDS contents and Chung et al. (2009a) reported an increase in RDS levels and a slight decrease in SDS and RS levels in normal corn starch upon annealing. Even with the same starch source enzyme digestibility characteristics vary upon annealing depending on the enzyme characteristics and annealing conditions (Table 2). The increase in RDS levels and a decrease in SDS and RS fractions on annealing could be due to the formation of porous structures (O'Brien and Wang, 2008) which allows greater accessibility of hydrolytic enzymes to penetrate into the granule (Chung et al., 2009a). Enhanced interactions between starch chains upon annealing could have caused an increase in RS levels (Chung et al., 2009b). Nutritional fractions of waxy corn and high amylose corn showed only slight changes on annealing (Wang et al., 2014) whereas, a decrease in RDS contents and increase in SDS and RS levels upon annealing were observed in waxy rice, normal rice and high amylose rice (Hung et al., 2016). However, Zeng et al. (2015) reported an increase in RDS contents and a decrease in SDS and RS contents of waxy rice upon annealing. Su et al. (2020) studied the effects of repeated and continuous ANN treatments on wheat starches and reported that SDS and RS contents of waxy and normal wheat starches increased with as annealing cycles ( 8 cycles, $12 \mathrm{~h}$ each) or duration (12-96 h) increased.

The impact of annealing on nutritional fractions of legume starches also varies widely. RDS levels were increased, SDS contents decreased and RS levels showed a slight increase in field pea and lentil starches upon annealing (Chung et al., 2009b). However, Chung et al. (2010) observed an increase in RDS and SDS levels and a decrease in RS contents in field pea and lentil starches upon annealing. A similar finding was also reported by Wang et al. (2013) for field pea starch where RDS and SDS levels were increased while RS levels decreased upon annealing. RDS and SDS levels were decreased and RS levels were increased in pinto bean, while a slight increase in RDS levels, a decrease in SDS levels and an increase in RS levels were observed in black bean starch upon annealing (Simsek et al., 2012). In navy bean starch, RDS levels did not show any change while SDS levels increased and RS levels decreased upon annealing (Chung et al., 2010). SDS content was increased and RS content decreased in grass pea starch upon ANN (Piecyk et al., 2018). Zou et al. (2019) studied the effects of repeated and continuous ANN treatments on mung bean starch and found that SDS and RS contents of mung bean starches increased with as annealing cycles ( 8 cycles, $12 \mathrm{~h}$ each) or duration (24-96 h) increased. There is a dearth of information on the impact of annealing on nutritional fractions of root and tuber starches. Song et al. (2014) reported an increase in RDS and SDS levels and a decrease in RS levels in sweet potato starch upon annealing. Annealing causes crystalline perfection and facilitates starch chain interactions, therefore, theoretically annealing should decrease starch susceptibility towards enzyme attack and RDS contents and increase SDS and RS fractions. However, in some starches RDS contents were increased while SDS and RS contents were decreased, suggesting that changes to granule surface (increase in granule porosity) on annealing could negate the effect of crystalline perfection and starch chain interactions on enzyme hydrolysis 
and thereby facilitates the entry of enzymes into the granule interior (Jayakody and Hoover, 2008).

The impact of gelatinization/cooking on starch nutritional fractions were studied in normal corn, field pea, lentil and navy bean starches (Chung et al., 2009b, 2010) and found that gelatinization increased RDS levels and decreased SDS and RS levels in all the starches compared to ungelatinized native counterparts indicating that the disruption of inter- and intra-molecular hydrogen bonds between starch chains during gelatinization, which increases the accessibility of the starch chains to enzyme attack. However, RDS contents decreased and SDS and RS contents increased after gelatinization of annealed starches compared to unmodified gelatinized starches suggesting that amylose-amylose interactions formed during annealing may resist the disruption during gelatinization (Chung et al., 2009b).

\subsection{Heat moisture treatment}

Heat-moisture treatment (HMT) is a hydrothermal modification which involves heating of starch granules at low moisture levels $(<35 \%$ moisture $\mathrm{w} / \mathrm{w})$ and high temperatures $\left(80-140{ }^{\circ} \mathrm{C}\right)$ for a certain period of time (1-24 h) (BeMiller and Huber, 2015; Li et al., 2020). Under these conditions, HMT allows increased molecular mobility of amylose and amylopectin, causing structural changes in both amorphous and crystalline regions of starch granules (BeMiller and Huber, 2015; Chen et al., 2015; Hoover and Manuel, 1996b; Jacobs and Delcour, 1998; Zavareze and Dias, 2011).

The main structural changes occur on HMT are increase in interactions between starch chains, change in the X-ray pattern from B/C to A+B or A-type (Ambigaipalan et al., 2014; Varatharajan et al., 2010, 2011; Zhang et al., 2010) reduction in relative crystallinity (Chung et al., 2009a, 2010; Huang et al., 2016; Lee et al., 2012; Varatharajan et al., 2011) formation of amylose-lipid complexes (Chen et al., 2015; Hoover and Manuel, 1996a) and reduction in the molecular order at the granule surface (Ambigaipalan et al., 2014; Chung et al., 2009a, 2009b, 2010; Huang et al., 2016; Kim and Huber, 2013; Varatharajan et al., 2011; Zeng et al., 2015). Structural changes within the amorphous and crystalline domains on HMT have been shown to alter the physicochemical properties such as, reduction in granular swelling and amylose leaching/solubility, elevation of gelatinization transition temperatures, decrease in gelatinization enthalpy (Chung et al., 2009b, 2010; Guneratne and Hoover, 2002; Guzel and Sayar, 2010; Huang et al., 2016; Kim and Huber, 2013) and increase in pasting temperature and decrease in pasting viscosities (Chen et al.,2015; Huang et al., 2016; Jiranuntakulm et al., 2011; Kim and Huber, 2013; San et al., 2014).

Susceptibility of heat moisture treated starches to enzyme hydrolysis has shown an increase or a decrease, even in the same starch type, indicating that the starch cultivar, HMT conditions, and enzyme assay characteristics play an important role in in vitro digestibility. Susceptibility towards porcine pancreatic $\alpha$-amylase of dull waxy maize, waxy maize, normal maize and amylomaize $\mathrm{V}$ decreased only marginally after HMT treatment and this reduction was attributed to formation of amylase-lipid complexes and/ or increased association of starch chains in the amorphous regions (Hoover and Manuel, 1996a). An increase in RDS levels and a decrease in SDS and RS contents were observed upon HMT in normal corn starch (Chung et al., 2009a). However, Chung et al. (2009b) reported an increase in RDS and RS levels and a decrease in SDS levels of normal corn starch after HMT. HMT has been shown to decrease RDS levels and increase SDS and RS contents of normal and high amylose maize starches, indicating the formation of densely packed starch fractions upon HMT (Wang et al., 2016). HMT has been shown to increase the susceptibility of high-, medium- and low-amylose rice starches towards bacterial $\alpha$-amylase and the digestibility of starches increased with an increase in the moisture content of HMT (Zavareze et al., 2010). Similarly, HMT has increased RDS and SDS contents and decreased RS contents of waxy rice, normal rice and corn starches (Jiranuntakulm et al., 2011). This increased digestibility could be due to disruption of the crystallites near the surface of the granule which facilitates the enzyme attack within the granule and dislocation of double helical structures in the amorphous region (Guneratne and Hoover, 2002). However, HMT has increased the RS contents of low-, medium- and high-amylose rice starches, where modified high-amylose starch had a higher RS content compared to low-and medium-amylose starch and RS levels of all the starches were increased with increasing moisture content of HMT (Zavareze et al., 2012). In high-, intermediate-low-amylose rice, normal rice and waxy rice, HMT has decreased RDS levels, SDS levels (except in normal rice where SDS levels decreased upon HMT) and increased RS contents and the highest RS content was observed in modified high amylose rice starch (Hung et al., 2016). HMT has decreased RDS and RS levels and increased SDS contents in waxy rice starch (Zeng et al., 2015). RDS contents were decreased and SDS and RS contents were increased upon HMT in wheat starch and the higher moisture content $(35 \%)$ resulted in the highest RS content (14.32\%) (Chen et al., 2015) suggesting that some interactions between the starch and protein and/or lipids form during HMT, thereby partly restricting accessibility of starch chains towards enzyme hydrolysis (Chen et al., 2015; Chung et al., 2009b). Zhang et al. (2020) studied the effects of repeated and continuous HMT treatments on wheat A- and B-starches. RDS and RS contents of wheat A-starch decreased and SDS content increased with repeating HMT cycles ( 6 cycles at $\left.120^{\circ} \mathrm{C}\right)$ whereas, RDS and SDS contents were increased and RS content decreased in wheat B-starch upon repeated HMT (Zhang et al., 2020).

In faba bean, black bean and pinto bean starches RDS contents increased, SDS contents decreased and RS contents increased after HMT at different temperatures $\left(80,100\right.$ and $120^{\circ} \mathrm{C}$ ) (Ambigaipalan et al., 2014). The increase in RDS levels in all the starches was attributed to the decrease in molecular order at the granular surface as a result of transformation of $\mathrm{A}+\mathrm{B}$ crystalline type to A-type. Atype crystallites are weaker than B-type crystallites since A-type has part of $\alpha-(1,6)$ branch points in the crystalline region compared to $\alpha-(1,6)$ branch points solely present in the amorphous regions in B-type, which makes A-type crystallites more susceptible towards enzyme attack (Gérard et al., 2001; Jane et al., 1997). Maximum RS content was observed at $80^{\circ} \mathrm{C}$ and then RS content decreased with increasing temperature in all the starches and the extents were different in different starches (Table 3) indicating that an increase or decrease in RS content on HMT may be influenced by HMT conditions, amylose content, proportion of $\mathrm{A}+\mathrm{B}$ type crystallites and extent of amylose-amylopectin co-crytallization (Ambigaipalan et al., 2014). An increase in susceptibility towards porcine pancreatic $\alpha$-amyalse of green arrow pea, lentil, pinto bean, black bean and field pea starches after HMT also has been also reported (Hoover and Manuel, 1996b). SDS content was increased and RS content was decreased in grass pea starch upon HMT (Piecyk et al., 2018). Chung et al. (2009b) has reported an increase in RDS and RS levels and a decrease in SDS contents in field pea and lentil starches upon HMT. However, an increase in RDS and SDS levels and a decrease in RS levels of pea and lentil starches upon HMT was also reported (Chung et al., 2010). These results prove that not only a single factor, but many factors affect the starch digestibility upon HMT.

RS contents of mung bean starches which were subjected to 


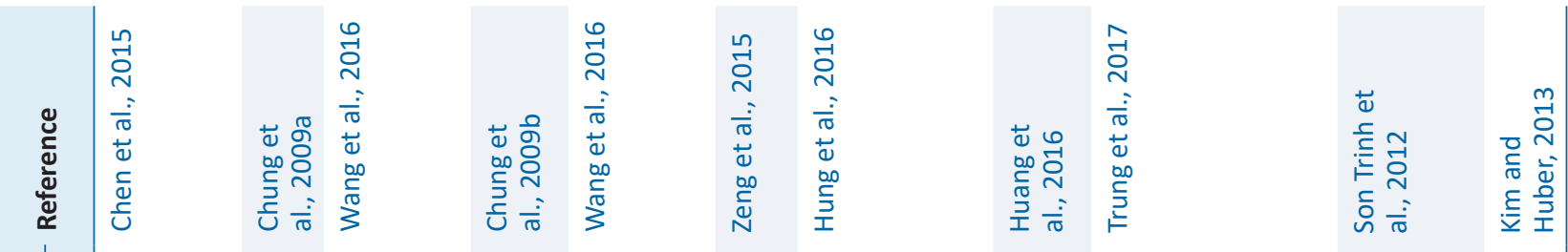

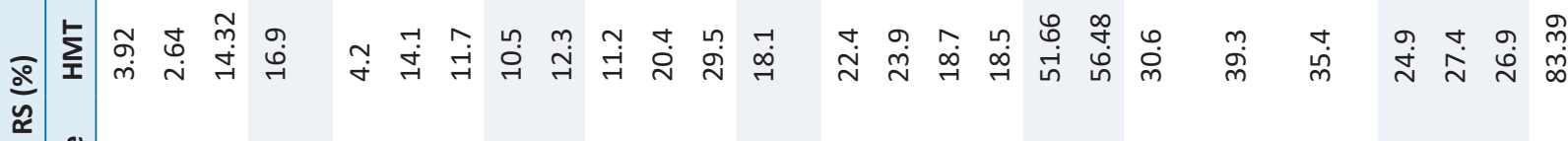

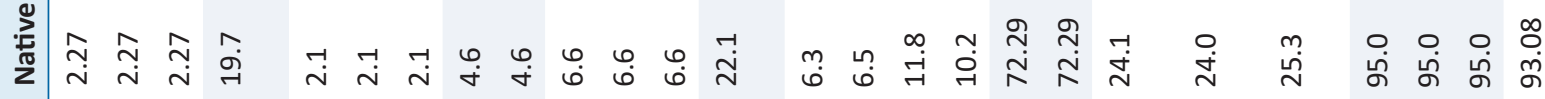

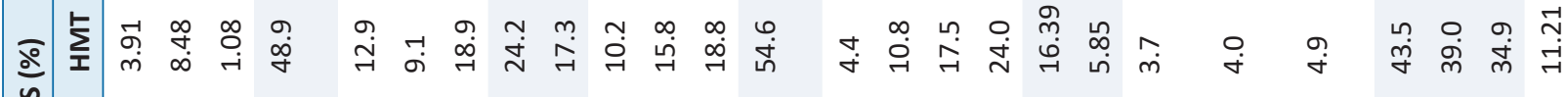

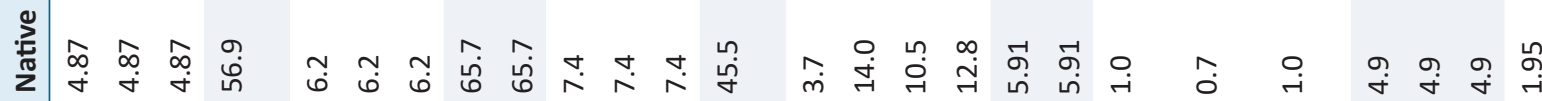

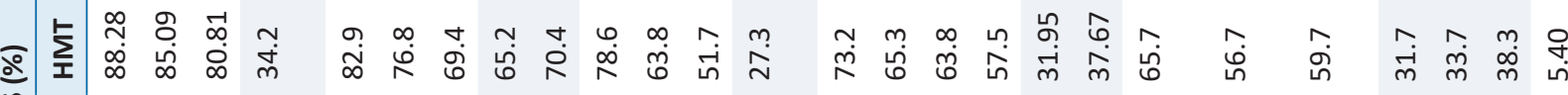

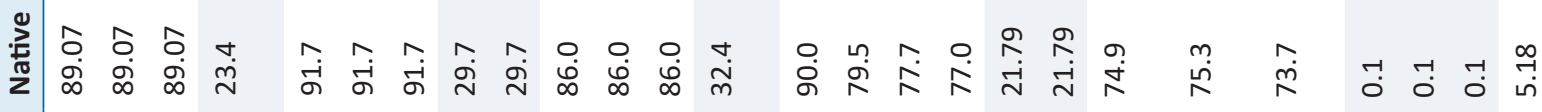

咅 군

혀 $\overline{\mathrm{g}}$

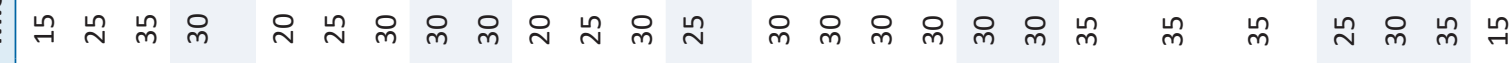

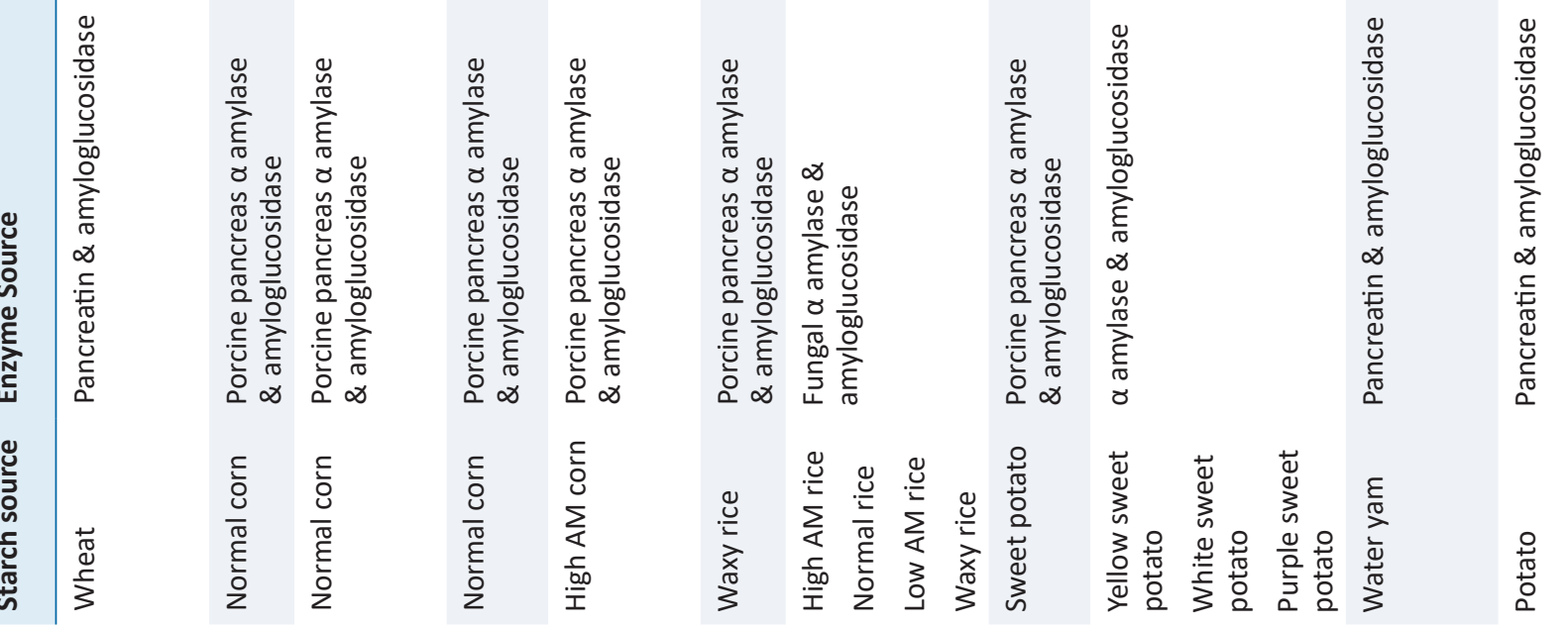




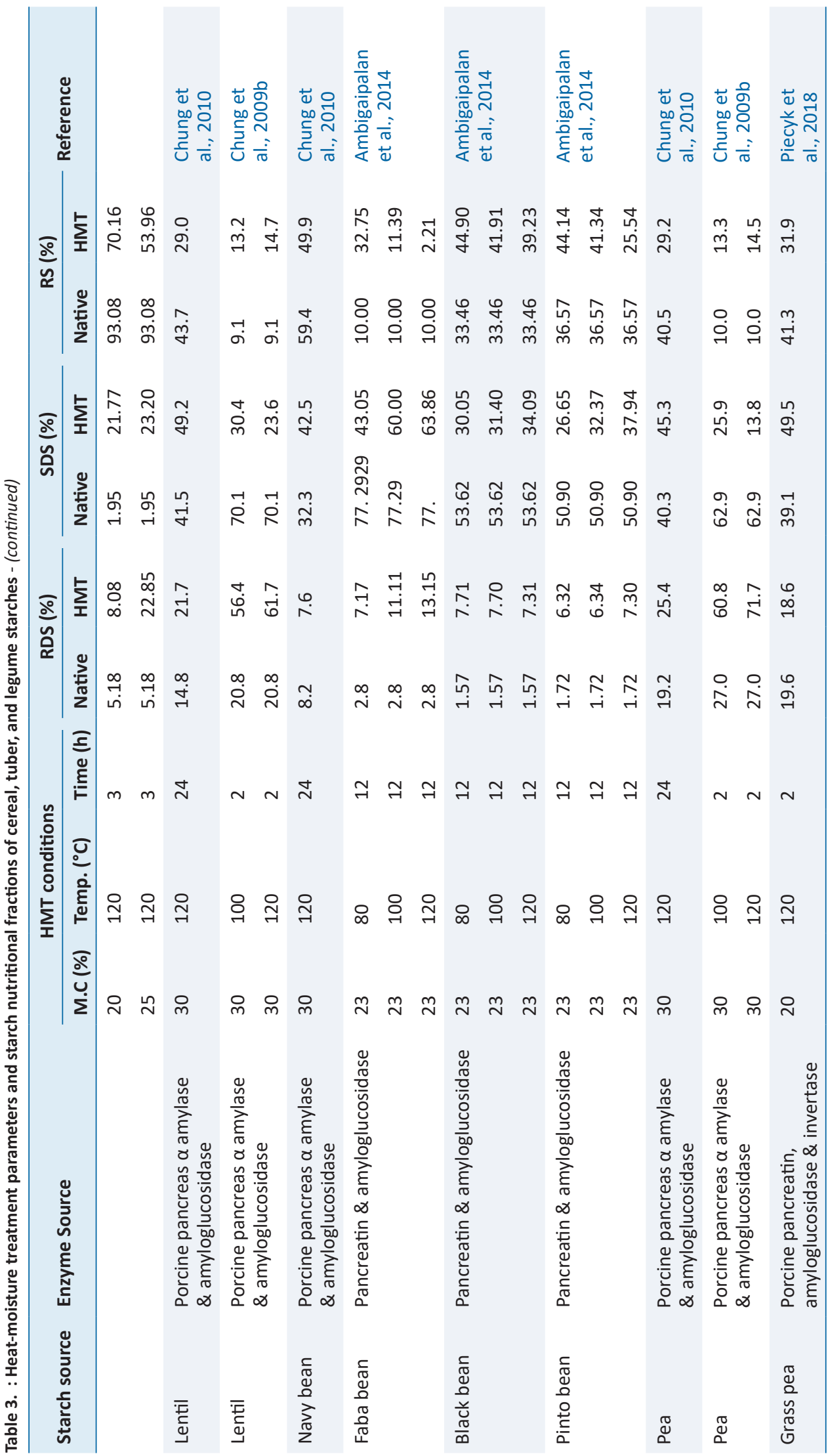


HMT at $120^{\circ} \mathrm{C}$ for $12 \mathrm{~h}$ with different moisture contents (15-35\%) resulted in an increase in RS content compared to native starch (RS content of $5.16 \%)$ and highest RS content $(45.15 \%)$ was obtained at $20 \%$ moisture content ( $\mathrm{Li}$ and Gao, 2010). Similar results were obtained for African locust bean starch subjected to HMT at different moisture contents (15-30\%), where RS content increased in modified starches and maximum RS content (50.14\%) was obtained at $20 \%$ moisture content compared to low RS content $(33.38 \%)$ in native starch (Sankhon et al., 2014) suggesting that the moisture content plays an important role in RS formation during HMT treatment. There was no significant change in RDS, SDS and RS levels in borlotti bean, chickpea and kidney bean starches which were subjected to HMT at $22 \%$ moisture content, $100{ }^{\circ} \mathrm{C}$ for $16 \mathrm{~h}$ (Guzel and Sayar, 2010).

Varatharajan et al. (2011) reported that HMT at $80{ }^{\circ} \mathrm{C}(27 \%$ moisture content, $16 \mathrm{~h}$ ) decreased hydrolysis in normal potato, but did not significantly influence hydrolysis in waxy potato, whereas HMT at 100,120 and $130{ }^{\circ} \mathrm{C}(27 \%$ moisture content, $16 \mathrm{~h})$ increased hydrolysis in both normal and waxy potato starch towards porcine pancreatic $\alpha$-amylase. There was no recognizable trend in the effect of HMT on $\alpha$-amylase hydrolysis for Canna starch at different moisture levels (Watcharatewinkul et al., 2010). HMT has been shown to increase RDS and SDS levels in waxy potato (Jiranuntakulm et al., 2011; Lee et al., 2012), normal potato (Jiranuntakulm et al., 2011; Kim and Huber, 2013), water yam (Son Trinh et al., 2012) and decrease RS levels in normal potato (Jiranuntakulm et al., 2011; Kim and Huber, 2013) and water yam (Son Trinh et al., 2012) starches. Vieira and Sarmento (2008) also reported an increased susceptibility of Peruvian carrot, sweet potato and ginger starches towards bacterial $\alpha$-amylase and amyloglucosidase. Heatmoisture treated potato (Perera and Hoover, 1998), true yam, cassava, potato, taro and new cocoyam (Guneratne and Hoover, 2002) starches have shown an increase in susceptibility towards porcine pancreatic $\alpha$-amylase compared to native counterparts. Son Trinh et al. (2012) studied nutritional fractions of water yam starch under various HMT conditions and found RDS content shows negative correlations with the moisture content and reaction time, whereas the RS content has a positive correlation with moisture content and SDS content has positive correlations with reaction time and moisture content. Therefore, the impact of reaction time on SDS formation was greater than that of moisture content, but the opposite for RS formation in water yam starch (Son Trinh et al., 2012).

Huang et al. (2016) used repeated HMT (30\% moisture content, $100{ }^{\circ} \mathrm{C}$ for $24 \mathrm{~h}$ ) in sweet potato starch and found that HMT increases RDS and SDS levels and decreases RS levels. Maximum SDS level (19.61\%) was observed at the third cycle and maximum RS content $(58.21 \%)$ was observed at the fifth cycle of HMT. The high SDS content at the third cycle could be the result of the damaged starch molecules and the less additional interactions between starch chains, and the high RS content at the fifth cycle may be caused by more additional interactions between starch chains, which hinder the disruption of starch molecules (Huang et al., 2016).

Thermostable SDS and RS fractions were studied by HMT of starch followed by gelatinization/cooking. RDS contents were increased and SDS and RS contents decreased after cooking in normal corn (Chung et al., 2009b), pea, lentil (Chung et al., 2009b, 2010), navy bean (Chung et al., 2010), sweet potato (Huang et al., 2016), potato (Kim and Huber, 2013), borlotti bean, chickpea, kidney bean (Guzel and Sayar, 2010) starches compared to native uncooked starches due to the granule disruption occurs during gelatinization. However, RDS contents were decreased and RS and SDS contents of cooked modified starches increased compared to unmodified gelatinized starches indicating the formation of strong- er amylose-amylose interactions upon HMT, which is the most effective parameter in the formation of nutritionally beneficial starch fractions with reduced digestibility (Chung et al., 2009b; Guzel and Sayar, 2010; Huang et al., 2016).

\subsection{Microwave heating}

Microwave energy is a non-ionizing energy source and it is delivered directly to the material through molecular interaction with the electromagnetic field. Since microwaves can transfer energy throughout the volume of the material it produces better quality products with higher yield in shorter processing time (Luo et al., 2006; Thostenson and Chou, 1999). Microwave energy is transferred to the material by the interaction of the electromagnetic field at the molecular level. The molecular structure affects the ability of the microwaves to interact with materials and transfer energy. Specially, the dielectric properties (dielectric constant and dielectric loss) determine the effect of the electromagnetic field on the material (Thostenson and Chou, 1999). Dry starches are not polarized at microwave frequencies and the dielectric properties depend primarily upon the free water content (Roebuck et al., 1972). Several studies have investigated the relationship between water content, temperature, salt addition and/or microwave frequencies on the dielectric properties of starches from different botanical origins and found that the dielectric properties are key factors in microwave heating of starch and strongly depend on the starch source, moisture content, temperature and microwave frequency (Brasoveanu and Nemtanu, 2014).

The mechanism of action of microwave irradiation on granular starch is not clearly defined. However, it can be hypothetically divide into following steps: (1) initial heating of starch granules caused by dielectric relaxation of water molecules, followed by (2) creation of high pressure inside the granules as a result of rapid increase in temperature causing vaporization of starch moisture and further causing (3) expansion of granules which starts from the centre where the highest temperature is and then it progresses in the entire volume leading (4) granules to degrade (Brasoveanu and Nemtanu, 2014). Microwave irradiation causes changes to physical and chemical properties of starches and these changes vary depending on the starch source and microwave processing parameters (Brasoveanu and Nemtanu, 2014). Swelling power of waxy barley starch decreased upon microwave treatment while it slightly increased in microwave treated non-waxy barley starch and the solubility of treated waxy barley starch was lower than that of native starch (Ma et al., 2020). Reduction in solubility and granular swelling upon microwave treatment could be due to rearrangement of crystalline regions within the starch granules, which might have randomly distributed in the native starch granule (Luo et al., 2006) and/or strengthening the interaction between starch chains (amylose-amylose and/or amylose-amylopectin) (Brasoveanu and Nemtanu, 2014). Microwave treatment has been shown to increase gelatinization transition temperatures and decrease gelatinization enthalpy of starches as a result of structural rearrangement occurring in the starch granule (Brasoveanu and Nemtanu, 2014). However, Zhong et al. (2020) reported that microwave treatment did not significantly change the gelatinization transitions temperatures and gelatinization enthalpy of rice starch.

There is a dearth of information available for digestibility characteristics of microwave irradiated starches. Microwave-heat moisture treated waxy and non-waxy rice starches have been shown slight increases in susceptibility towards porcine pancreatic $\alpha$-amylase hydrolysis compared to the native starches as microwave power levels were increased (Anderson and Guraya, 2006). 
They further observed that in non-waxy rice starch, the slight increase in digestibility did not take place until much higher microwave power levels were used whereas, there was a uniform increase in digestibility of waxy rice starch as power level increased, indicating that the granular structure of waxy starch permitted more rapid heat penetration of granules during microwave treatment. Similar results were obtained for wheat and corn starches where susceptibility towards porcine pancreatic $\alpha$-amylase did not change when increasing the microwave energy levels (Hodsagi et al., 2012). Short-time (1-4 min) microwave treatment of high amylose maize starch showed an increased susceptibility towards pancreatin and amyloglucosidase digestion causing a reduction in RS content. The digestions rates were increased with increasing microwave treatment time, while RS content decreased from 54.8 to $29.5 \%$ when the treatment time increased from 1 to $4 \mathrm{~min}$ (Zhong et al., 2019). However, wheat starch showed a decrease in susceptibility towards porcine $\alpha$-amylase with increasing heating time and further enzyme susceptibility decreased following storage for $120 \mathrm{~h}$ was observed indicating the increase in polymer reassociation (Palav and Seetharaman, 2007). Rice starch which was microwave treated ( $8 \mathrm{~W}$ per gram of starch slurry for $3 \mathrm{~min}$ ) and stored $\left(4^{\circ} \mathrm{C}\right.$ for $72 \mathrm{~h}$ ) showed increased SDS level and decreased digestibility rate compared to conventionally cooked counterpart indicating that the microwave treatment has enhanced molecular reassembly during digestion ( $\mathrm{Li}$ et al., 2020).

Microwave treatment increased digestibility of waxy, normal and high amylose barley starches showing increased RDS (from 16.3 to $37.5 \%$ in waxy barley, from 6.6 to $47.7 \%$ in normal barley and from 10.7 to $46.1 \%$ in high amylose barley) contents and decreased SDS (from 20.8 to $8.1 \%$ in waxy barley, from 41.6 to $11.4 \%$ in normal barley and from 23.5 to $8.1 \%$ in high amylose barley) and RS (from 9.2 to $0.8 \%$ in waxy barley, from 16.9 to $6.1 \%$ in normal barley and from 24.0 to $4.0 \%$ in high amylose barley) contents compared to native starches (Emami et al., 2012). The level of SDS in microwave treated barley starches decreased with an increase in microwave power level from $330 \mathrm{~W}$ to $713 \mathrm{~W}$, whereas the levels of RDS in normal and waxy barley and the level of RS in high amylose barley (from 4.0 to $10.5 \%$ ) increased. The level of RDS in high amylose barley and the RS levels in normal and waxy barley were not affected markedly by power level. The more rapid heating associated with higher power levels resulted in a higher degree of starch gelatinization and higher starch digestibility in all barley types (Emami et al., 2012).

Zhang et al. (2009) observed that microwave power has an evident effect on porcine pancreatic $\alpha$-amylase digestibility of Canna starch, which increased to its highest levels when $800 \mathrm{~W}$ of microwave power was used indicating that both low $(400 \mathrm{~W})$ and high $(1,000 \mathrm{~W})$ microwave powers were beneficial to the formation of RS. In Canna starch, with an increase in moisture content of microwave treatment from 20 to $35 \%$, enzymatic digestibility decreased gradually, suggesting that the RS and SDS contents increased with increasing moisture content of microwave heat-moisture treatment (Zhang et al., 2009). Microwave heat-moisture treatment had a significant impact on nutritional fractions of Canna starch, where RS content in modified starch was higher (from 27.73 to $55.52 \%$ ) than native starch and RDS content was reduced by a half (from 60.50 to $32.62 \%$ ) in the treated starch, while SDS content almost remained unchanged after the microwave treatment (Zhang et al., 2010).

The results obtained in different studies on enzyme digestibility and nutritional fractions indicate that microwave treatment causes significant changes in the crystalline structure of the starches and that these changes were influenced in a complex manner by the factors such as moisture content, microwave power level and tem- perature as well as the variations in the method used to evaluate the starch nutritional fractions. Therefore, it is difficult to find a clear relationship on how microwave irradiation conditions affect enzyme digestibility and nutritional.

\section{Non-thermal modifications of starch}

\subsection{High hydrostatic pressure treatment}

High hydrostatic pressure (HHP) is a non-thermal processing technology which is suitable for the production of minimally processed foods because HPP affects only secondary and tertiary bonds not primary or covalent bonds. Therefore, vitamins, pigments and flavor substances which are affected by traditional thermal processing techniques remain intact when subjected to HPP. Another advantage over thermal processing is that the pressure acts immediately and is not dependent on the size and shape of the product (Stute et al., 1996). The investigations on the effect of HHP on starch can be categorized into three groups as: (1) application of pressure which is not high enough to gelatinize starch, (2) pressure application on almost dry starch, and (3) use of ultra-high pressure treatment which is carried out in excess water and at a pressure above $400 \mathrm{MPa}$ (Katopo et al., 2002; Stute et al., 1996). Stute et al. (1996) showed that maize, waxy maize, high amylose maize, rice, waxy rice, potato, canna, lotus root, taro, water chestnut, arrow root and smooth pea starches when subjected to HHP (350-600 $\mathrm{MPa}, 25 \%$ moisture) treatment were gelatinized, but retained their granular form.

Gelatinization can be achieved at low pressure (400-800 MPa) for A-type starches such as wheat and maize, but high pressure (800-900 MPa) is needed for gelatinization of potato starch (Btype) (Stute et al., 1996). Some studies have shown that sensitivity of C-type starches to HHP is in between A-type and B-type (Jayaprakasha et al., 2000). X-ray diffraction patterns of A-type starches such as waxy maize, normal maize and rice showed transformation from A- to B-like pattern, but this transformation was weak, while potato and high amylose maize starches kept their original X-ray pattern (B-type) after HPP treatment (690 MPa, 1:1 and 2:1 water: starch ratio) (Katopo et al., 2002). HPP treatment has been shown to decrease gelatinization transition temperatures and gelatinization enthalpy of different starches (Błaszczak et al., 2005; Katopo et al., 2002; Liu et al., 2008; Stute et al., 1996). This decrease indicates the damage and loss of molecular order and crystallinity as a result of pressurization (Katopo et al., 2002).

There are very few studies which have evaluated digestibility and/or nutritional fractions of HHP treated starches. HPP treatment at 200 and $400 \mathrm{MPa}$ resulted a lower starch digestion rate compared to the native counterpart while HPP treatment at 600 , 800 and 1,000 MPa significantly enhanced digestion rate of high amylose corn starch when the under similar moisture content (Shen et al., 2018). Furthermore, with different moisture contents (30-70\%) digestion rates of high amylose corn starch did not differ significantly at given pressures (200-800 MPa) except at $1,000 \mathrm{MPa}$ suggesting that applied pressure plays an important role rather than moisture content in altering starch digestion (Shen et al., 2018). Wang et al. (2017) compared the effect of HPP at 200-600 MPa for $30 \mathrm{~min}$ on enzyme digestion of wheat, yam, and potato starches and reported that significant differences in enzyme hydrolysis were observed in wheat and yam starches at $600 \mathrm{MPa}$ compared to their native counterparts, while no changes in digestion were observed in potato starch even at $600 \mathrm{MPa}$. Bauer et al. (2005) compared the RS formation of wheat starch by different 
methods and found that HHP (500 MPa for $15 \mathrm{~min}$ ) was not an effective way to produce RS. Storage at room temperature or freezethawing of pressurized wheat starch also did not increase the RS content, however, storage at high temperature $\left(52{ }^{\circ} \mathrm{C}\right.$ for $\left.24 \mathrm{~h}\right)$ following pressure treatment resulted in higher $\mathrm{RS}$ contents in comparison to heat-gelatinized wheat starch (Bauer et al., 2005). The HHP treated (600 MPa, $30 \mathrm{~min}$ ) non-waxy rice starch contained a higher SDS content of $36.7 \%$ compared to the heat-gelatinized starch $(33.9 \%)$ immediately after 7 days of storage at $4{ }^{\circ} \mathrm{C}$. The higher SDS content after HHP treatment was mainly attributed to the intact starch granules retained in the HHP treatment and formation of amylose-lipid complexes (Tian et al., 2014). They observed higher SDS contents in HHP treated waxy rice starch (38.7\%) compared to heat-gelatinized waxy rice (36.3\%) after similar storage conditions. However, high SDS levels obtained in this study for waxy rice starch are not in agreement with results obtained by Hu et al. (2011) where waxy rice starch granules were almost completely broken.

There was no significant difference in RDS, SDS and RS levels of rice starch treated with $200 \mathrm{MPa}$ for $30 \mathrm{~min}$. However, RDS (from 40.30 to $44.18 \%$ ) and SDS (from 24.11 to $40.42 \%$ ) contents increased and RS content of rice starch decreased (from 35.59 to $15.40 \%$ ) compared to native starch when treated at $600 \mathrm{MPa}$ for 30 min (Deng et al., 2014). It is believed that the pressure could force water into granules, especially amorphous regions and breaks the crystal structure of starch (BeMiller and Huber, 2015; Li et al., 2012). As more granules were disrupted with HHP treatment, enzymes can access easily to the inner structure increasing the digestibility (Deng et al., 2014). Since there is a dearth of information available for digestion characteristics of HHP treated starches, it is difficult to comprehensively evaluate the impact of HHP on starch nutritional fractions. At present, available data shows that there is possibility of using HHP as an alternative to traditional treatment for improving nutritional properties of starches. Further detailed investigations are needed with different starch sources and process conditions to develop HHP as a feasible starch modification technique.

\subsection{Pulsed electric field treatment}

Pulsed electric field (PEF) technology is a non-thermal food preservation method compared to traditional thermal pasteurization, which kills most pathogenic or spoilage microorganisms, inactivates enzymes, and also minimizes the loss of taste, color, texture, nutrients, and heat sensitive functional components of foods (Jeyamkondan et al., 1999) In PEF, a pumpable liquid material is treated in a processing chamber with high intensity electric pulses (over $10 \mathrm{kV} \mathrm{cm}^{-1}$ ) at short duration (less than $40 \mu \mathrm{s}$ ). Several studies have demonstrated that the PEF treatment has prominent advantages such as low processing temperature, continuous processing nature, short treatment time, and uniform treatment intensity (Han et al., 2012; Zeng et al., 2016).

The effects of PEF on the physicochemical properties of corn (Han et al., 2009b), waxy rice (Zeng et al., 2016), potato (Li et al., 2019; Han et al., 2009a), wheat and pea (Li et al., 2019) and tapioca (Han et al., 2012) starches have been studied. PEF treatment damages the outer part of starch granule and therefore, inner of starch granule could more effectively absorb water and swell resulting aggregation of modified granules with each other or with small granules, which led to an increase of granule size (Han et al., 2009a, 2009b). PEF treatment has been shown to decrease relative crystallinity, gelatinization transition temperatures and gelatinization enthalpy of different starches (Han et al., 2009a, 2009b,
2012; Zeng et al., 2016) suggesting that the treated starches were more sensitive to be gelatinized due to the rearrangement and destruction of starch molecular structure and crystallinity after PEF treatment (Han et al., 2009b). Relative crystallinity decreased with increasing field intensity $\left(2.86-8.57 \mathrm{kVcm}^{-1}\right)$ in PEF treated wheat and potato starches, while crystallinity only slightly changed in PEF treated pea starch (Li et al., 2019).

At present, only few studies have investigated starch nutritional fractions of PEF treated starches. RDS levels increased (from 32.4 to $37.4 \%$ ) and SDS (from 45.5 to $42.0 \%$ ) and RS (from 22.1 to 20.7\%) levels decreased after PEF treatment in waxy rice starch and furthermore, with the increase of PEF electric field strength (from 30 to $50 \mathrm{kV} \mathrm{cm}{ }^{-1}$ ), RDS levels increased (from 37.4 to $50.4 \%$ ), while SDS levels (from 42.0 to $35.2 \%$ ) and RS levels (from 20.7 to $14.4 \%$ ) decreased (Zeng et al., 2016). RDS contents increased in PEF treated wheat, potato, and pea starches while RS contents increased only in wheat and potato starches with increasing field intensity $\left(2.86-8.57 \mathrm{kVcm}^{-1}\right)$ (Li et al., 2019). PEF treated rice starch showed higher RDS levels and lower SDS levels with different field intensities $\left(2.86-8.57 \mathrm{kVcm}^{-1}\right)$ while RS contents remained unchanged in comparison to native starch (Wu et al., 2019). The disruption of starch granule packaging/starch crystallites may have exposed the $\alpha-(1,4)$ glycosidic bonds and/ or $\alpha-(1,6)$ glycosidic bonds that were previously buried within the starch crystallites facilitating the entry of the enzyme into the granule interior (Zeng et al., 2016).

\section{Dual modification}

Dual modification involves a combination of two modification techniques. Combination of chemical and physical methods, chemical and enzymatic methods and two chemical methods are used in order to improve the properties and uses of starches (Ashogbon and Akintayo, 2014). The first modification rearranges the starch chains and structures of the granules for the second modification in the physical dual modification. In general, the properties of the dual modified starches are mainly resulting from the second modification and sometimes the effects can be a combination of both modifications (Ashogbon, 2020). There are a few studies for effect of physical dual modification on in vitro digestibility of starches, where HMT in combination with ANN (Chung et al., 2009a, 2010; Farias et al., 2019; Zeng et al., 2015) and extrusion (Yan et al., 2019). ANN-HMT and HMT-ANN treatments have been shown to restrict granule swelling, solubility and amylose leaching in waxy rice (Zeng et al., 2015), pea, lentil and navy bean starches (Chung et al., 2010) whereas a decrease in swelling factor and an increase in amylose leaching was observed in normal corn starch after dual modification (Chung et al., 2009a). Relative crystallinity and molecular order at the granule surface have been shown to increase or decrease upon dual modification in varying extents in different starches (Chung et al., 2009a, 2010; Zeng et al., 2015). Gelatinization transition temperatures have increased compared to native starch after dual modification corn (Chung et al., 2009a), waxy rice (Zeng et al., 2015), pea, lentil and navy bean (Chung et al., 2010) and bean starches (Farias et al., 2019) whereas gelatinization enthalpy increased, decreased or remained unchanged in those starches compared to native counterparts in different dual modifications (ANN-HMT and HMT-ANN). These variations in different starch types can be due to interplay between two factors; disruption of crystallites during HMT which were perfected on ANN (in ANNHMT) and better alignment of crystallites during ANN which 
Table 4. : Starch nutritional fractions of native and dual modified starches from different botanical origins

\begin{tabular}{|c|c|c|c|c|c|c|c|c|}
\hline \multirow{2}{*}{ Starch source } & \multirow{2}{*}{$\begin{array}{l}\text { Modifica- } \\
\text { tion type }\end{array}$} & \multicolumn{2}{|c|}{ RDS (\%) } & \multicolumn{2}{|c|}{ SDS (\%) } & \multicolumn{2}{|c|}{ RS (\%) } & \multirow{2}{*}{ Reference } \\
\hline & & Native & Modified & Native & Modified & Native & Modified & \\
\hline \multirow[t]{2}{*}{ Waxy rice } & ANN-HMT & 32.4 & 34.2 & 45.5 & 49.3 & 22.1 & 16.5 & Zeng et al., 2015 \\
\hline & HMT-ANN & 32.4 & 45.8 & 45.5 & 40.5 & 22.1 & 13.7 & Zeng et al., 2015 \\
\hline \multirow[t]{2}{*}{ Normal maize } & ANN-HMT & 23.4 & 33.1 & 56.9 & 49.7 & 19.7 & 17.3 & Chung et al., 2009a \\
\hline & HMT-ANN & 23.4 & 29.1 & 56.9 & 51.2 & 19.7 & 19.7 & Chung et al., 2009a \\
\hline \multirow[t]{2}{*}{ Pea } & ANN-HMT & 19.2 & 27.0 & 40.3 & 44.8 & 40.5 & 28.1 & Chung et al., 2010 \\
\hline & HMT-ANN & 19.2 & 24.4 & 40.3 & 44.4 & 40.5 & 31.2 & Chung et al., 2010 \\
\hline \multirow[t]{2}{*}{ Lentil } & ANN-HMT & 14.8 & 24.6 & 41.5 & 46.5 & 43.7 & 28.8 & Chung et al., 2010 \\
\hline & HMT-ANN & 14.8 & 21.2 & 41.5 & 45.1 & 43.7 & 33.7 & Chung et al., 2010 \\
\hline \multirow[t]{2}{*}{ Navy bean } & ANN-HMT & 8.2 & 7.2 & 32.3 & 39.5 & 59.4 & 53.3 & Chung et al., 2010 \\
\hline & HMT-ANN & 8.2 & 6.3 & 32.3 & 38.8 & 59.4 & 54.9 & Chung et al., 2010 \\
\hline
\end{tabular}

were disrupted on HMT (in HMT-ANN) (Chung et al., 2009a, 2010; Zeng et al., 2015). The combination of extrusion and HMT has increased swelling power, solubility and gelatinization transition temperatures and decreased relative crystallinity and gelatinization enthalpy of corn starch compared to native counterpart (Yan et al., 2019). However, compared to the extruded starch the dual modification has increased crystallinity and gelatinization parameters indicating that the dual modification has increased the thermal stability of corn starch (Yan et al., 2019).

Both HMT-ANN and ANN-HMT modifications have been shown to increase RDS and SDS contents in normal corn starch whereas RS content decreased upon ANN-HMT and remain unchanged upon HMT-ANN (Chung et al., 2009a). In pea, lentil and navy bean starches, HMT-ANN decreased RDS and SDS levels and increased RS levels as compared to HMT starches indicating perfection of crystallites that were disrupted on HMT. ANN-HMT increased RDS and SDS levels and decreased RS levels in pea and lentil compared to ANN starches indicating disruption of perfected crystallites (Chung et al., 2010). However, Zeng et al. (2015) observed an increase in RDS and a decrease in SDS and RS contents on HMT-ANN and compared to HMT and a decrease in RDS, an increase in SDS and no change in RS content was observed on ANN-HMT compared to ANN. Crystalline disruption may have exposed the $\alpha-(1,4)$ and/or $\alpha-(1,6)$ linkages that were previously buried within the starch crystallites, and thus enhance accessibility towards enzyme attack (Zeng et al., 2015). The combination of extrusion and HMT increased RDS and SDS contents and decreased RS content compared to native corn starch. However, dual modification decreased RDS content and increased RS content compared to extruded corn starch indicating that the dual modification increased the interactions between starch chains compared to single extrusion treatment resulting better resistance to enzyme hydrolysis (Yan et al., 2019). The amounts of RDS, SDS and RS contents of native and dual modified starches from different botanical sources are presented in Table 4.

Chung et al. (2010) evaluated the digestibility characteristics of modified and gelatinized pea, lentil and navy bean starches and found that both ANN-HMT and HMT-ANN decrease RDS content and increase SDS and RS levels in gelatinized starches compared to unmodified gelatinized starches indicating the formation of thermos-stable AM-AM interactions during modification which can restrict disruption during gelatinization (Chung et al., 2009b, 2010).

\section{Conclusion}

Both thermal and non-thermal modifications alter starch digestibility as well as other physicochemical properties. The changes occur in starch structure as a result of different physical modifications directly affect the susceptibility towards enzyme hydrolysis of starches and the contents of starch nutritional fractions, which ultimately affects the bioactive properties caused by RS. There is a vast amount of information about the impact of ANN and HMT on starch nutritional fractions but there are only a few studies regarding the other physical modifications techniques. However, it is difficult to find a relationship between different modification techniques and starch nutritional fractions since different studies have used different processing conditions and enzyme assay conditions. More studies that investigate techniques other than ANN and HMT, as well as dual modifications are needed to develop reliable processing technique with high RS contents since RS has the potential to be used as a natural bioactive component in food applications. It is also important to develop a standard method (with particular enzyme source, concentration and digestion time) to evaluate impact on starch nutritional fractions for future studies which will enable enhanced comparison between different processing techniques and starch sources.

\section{Acknowledgments}

This review article is dedicated to the memory of Professor R. Hoover who was a gentleman and a scholar.

\section{References}

Adeleye, O.O., Awodiran, S.T., Ajayi, A.O., and Ogunmoyela, T.F. (2020). Influence of extrusion cooking on physicochemical properties and starch digestion kinetics of Sphenostylis stenocarpa, Cajanus cajan, and Vigna subterranean grains. Plos one. 15(12): e0242697.

Agustiniano-Osornio, J.C., Gonzalez-Soto, R.A., Flores-Huicochea, E., ManriqueQuevedo, N., Sanchez-Hernandez, L., and Bello-Perez, L.A. (2005). Resistant starchproduction from mango starch using a singlescrew extruder. J. Sci. Food Agric. 85: 2105-2110.

Alonso, R., Aguirre, A., and Marzo, F. (2000). Effects of extrusion and traditional processing methods on antinutrients and in vitro digestibil- 
ity of protein and starch in feba and kindey beans. Food Chem. 68 159-165.

Ambigaipalan, P., Hoover, R., Donner, E., and Liu, Q. (2014). Starch chain interactions within the amorphous and crystalline domains of pulse starches during heat-moisture treatment at different temperatures and their impact on physicochemical properties. Food Chem. 143 175-184.

Amini, A., Khalili, L., Keshtiban, A.K., and Homayouni, A. (2016). Resistant starch as a bioactive compound in colorectal cancer prevention. Bioactive Foods in Health Pro. pp. 773-780.

Anderson, A.K., and Guraya, H.S. (2006). Effects of microwave heat-moisture treatment on properties of waxy and non-waxy rice starches. Food Chem. 97: 318-323.

Arora, B., Yoon, A., Sriram, M., Singha, P., and Rizvi, S.S. (2020). Reactive extrusion: A review of the physicochemical changes in food systems. Inn. Food Sci. and Emerging Tech. 64: 102429.

Ashogbon, A.O. (2018). Current Research Addressing Physical Modification of Starch from Various Botanical Sources. Global Nutri. and Dietetics. 1(1): 1-7.

Ashogbon, A.O. (2020). Dual modification of various starches: Synthesis, properties and applications. Food Chem. 128325.

Ashogbon, A.O., and Akintayo, E.T. (2014). Recent trend in the physical and chemical modification of starches from different botanical sources: A review. Starch/Stärke 66: 41-57.

Bauer, B.A., Wiehle, T., and Knorr, D. (2005). Impact of high hydrostatic pressure treatment on the resistant starch content of wheat starch. Starch/Stärke 57: 124-133.

Bello-Perez, L.A., Flores-Silva, P.C., Agama-Acevedo, E., and Tovar, J. (2020). Starch digestibility: past, present, and future. J. Sci. Food Agric. $100(14)$ : 5009-5016.

BeMiller, J.N., and Huber, K.C. (2015). Physical modification of food starch functionalities. Annu. Rev. Food Sci. Technol. 6: 19-69.

Błaszczak, W., Valverde, S., and Fornal, J. (2005). Effect of high pressure on the structure of potato starch. Carbo. Poly. 59: 377-383.

Brasoveanu, M., and Nemtanu, M.R. (2014). Behaviour of starch exposed to microwave radiation treatment -Review. Starch/Stärke. 66: 3-14.

Camire, M.E. (2000). Chemical and nutritional changes in foodduring extrusion. In: Riaz, M.N. (Ed.). Extruders in Food Applications. CRC Press, Boca Raton, FL, pp. 127-147.

Chanvrier, H., Uthayakumaran, S., Appelqvist, I.A.M., Gidley, M.J., Gilbert, E.P., and López-Rubio, A. (2007). Influence of storage conditions on the structure, thermal behavior, and formation of enzyme-resistant starch in extruded starches. J. of Agri. and Food Chem. 55: 9883-9890.

Chen, X., He, X., Fu, X., and Huang, Q. (2015). In vitro digestion and physicochemical properties of wheat starch/flour modified by heat-moisture treatment. J. of Cereal Sci. 63: 109-115.

Chung, H.J., Hoover, R., and Liu, Q. (2009a). The impact of single and dual hydrothermal modifications on the molecular structure and physicochemical properties of normal corn starch. Int. J. of Bio. Macro. 44 203-210.

Chung, H.J., Liu, Q., and Hoover, R. (2009b). Impact of annealing and heat-moisture treatment on rapidly digestible, slowly digestible, and resistant starch levels in native and gelatinized corn, pea, and lentil starches. Carbo. Poly. 74: 436-447.

Chung, H.J., Liu, Q., and Hoover, R. (2010). Effect of single and dual hydrothermal treatments on the crystalline structure, thermal properties, and nutritional fractions of pea, lentil, and navy bean starches. Food Res. Int. 43: 501-508.

Colonna, P., Doublier, J.L., Melcion, J.P., Demonredon, F., and Mercier, C. (1984). Extrusion cooking and drum drying of wheat starch. 1. Physical and macromolecular modifications. Cereal Chem. 61: 538-543.

Coulon, D.B., Page, R., Raggio, A.M., Guice, J., Marx, B., Gourineni, V., Stewart, M.L., and Keenan, M.J. (2020). Novel Resistant Starch Type 4 Products of Different Starch Origins, Production Methods, and Amounts Are Not Equally Fermented when Fed to Sprague-Dawley Rats. Mole. Nutri. and Food Res. 64(2): 1900901.

DeMartino, P., and Cockburn, D.W. (2020). Resistant starch: impact on the gut microbiome and health. Cur. Opi. in Biotech. 61: 66-71.

Deng, Y., Jin, Y., Luo, Y., Zhong, Y., Yue, J., Song, X., and Zhao, Y. (2014) Impact of continuous or cycle high hydrostatic pressure on the ultrastructure and digestibility of rice starch granules. J. of Cereal Sci.
60(2): 302-310.

Dias, A.R.G., Zavareze, E.d.R., Spier, F., de Castro, L.A.S., and Gutkoski, L.C. (2010). Effects of annealing on the physicochemical properties and enzymatic susceptibility of rice starches with different amylose contents. Food Chem. 123: 711-719.

Dona, A.C., Pages, G., Gilbert, R.G., and Kuchel, P.W. (2010). Digestion of starch: In vivo and in vitro kinetic models used to characterise oligosaccharide or glucose release-review. Carbo. Poly. 80: 599-617.

Emami, S., Perera, A., Meda, V., and Tyler, R.T. (2012). Effect of microwave treatment on starch digestibility and physico-chemical properties of three barley types. Food Bioprocess Tech. 5: 2266-2274

Englyst, K.N., Englyst, H.N., Hudson, G.J., Cole, T.J., and Cummings, J.H. (1999). Rapidly available glucose in foods: an in vitro measurement that reflects the glycemic response. Am. J. Clin. Nutr. 69: 448-454.

Farias, F.O., Granza, A.G., Travalini, A.P., de Oliveira, C.S., Schnitzler, E., and Demiate, I.M. (2019). Evaluation of the effects of single and dual hydrothermal treatments on the properties of Carioca bean (Phaseolus vulgaris L.) starch. Int. Food Res. J. 26(1): 337-344

Fuentes-Zaragoza, E., Riquelme-Navarrete, M.J., Sánchez-Zapata, E., and Pérez-Álvarez, J.A. (2010). Resistant starch as functional ingredient: A review. Food Res. Int. 43: 931-942.

Gérard, C., Colonna, P., Buléon, A., and Planchot, V. (2001). Amylolysis of maize mutant starches. J. of the Sci. of Food and Agri. 81: 1281-1287.

Guneratne, A., and Hoover, R. (2002). Effect of heat-moisture treatment on the structure and physicochemical properties of tuber and root starches. Carbo. Poly. 49: 425-437.

Guo, J., Tan, L., and Kong, L. (2020). Impact of dietary intake of resistant starch on obesity and associated metabolic profiles in human: a systematic review of the literature. Cri. Rev. in Food Sci. and Nutri. 1-17.

Guzel, D., and Sayar, S. (2010). Digestion profiles and some physicochemical properties of native and modified borlotti bean, chickpea and white kidney bean starches. Food Res. Int. 43: 2132-2137.

Han, Z., Zeng, X.A., Yu, S.J., Zhang, B.S., and Chen, X.D. (2009a). Effects of pulsed electric fields (PEF) treatment on physicochemical properties of potato starch. Inn. Food Sci. and Emerging Tech. 10(4): 481-485.

Han, Z., Zeng, X., Zhang, B., and Yu, S. (2009b). Effects of pulsed electric fields (PEF) treatment on the properties of corn starch. J. of Food Engi. 93(3): 318-323.

Han, Z., Zeng, X.A., Fu, N., Yu, S.J., Chen, X.D., and Kennedy, J.F. (2012). Effects of pulsed electric field treatments on some properties of tapioca starch. Carbo. Poly. 89: 1012-1017.

Hasjim, J., Ai, Y., and Jane, J.L. (2013). Novel applications of amylose-lipid complex as resistant starch type 5. Resistant Starch. 79-94.

Hodsagi, M., Jambor, A., Juhasz, E., Gergely, S., Gelencser, T., and Salgo, A (2012). Effects of microwave heating on native and resistant starches. Acta Alimentaria. 41: 233-247.

Hoover, R., and Manuel, H. (1996a). The effect of heat-moisture treatment on the structure and physicochemical properties of normal maize waxy maize, dull waxy maize and amylomaize $V$ starches. J. of Cereal Sci. 23: 153-162.

Hoover, R., and Manuel, H. (1996b). Effect of heat-moisture treatment on the structure and physicochemical properties of legume starches. Food Res. Int. 29: 731-750.

Hoover, R., and Vasanthan, T. (1994). The effect of annealing on the physicochemical properties of wheat, oat, potato and lentil starches. J. of Food Biochem. 17: 303-325.

Htoon, A., Shresta, A.K., Flanagan, B.M., Lopez-Rubio, A., Bird, A.R., Gilbert, E.P., and Gidley, M.J. (2009). Effects of processing high amylose maize starchesunder controlled conditions on structural organization andamylose digestibility. Carbo. Poly. 75: 236-245.

Hu, X., Xu, X., Jin, Z., Tian, Y., Bai, Y., and Xie, Z. (2011). Retrogradation properties of rice starch gelatinized by heat and high hydrostatic pressure (HHP). J. of Food Engi. 106: 262-266.

Huang, T.-T., Zhou, D.-N., Jin, Z.-Y., Xu, X.-M., and Chen, H.-Q. (2016). Effect of repeated heat-moisture treatments on digestibility, physicochemical and structural properties of sweet potato starch. Food Hydro. 54: 202-210.

Hung, P.V., Chau, H.T., and Phi, N.T.L. (2016). In vitro digestibility and in vivo glucose response of native and physically modified rice starches varying amylose contents. Food Chem. 191: 74-80.

Jacobs, H., and Delcour, J. (1998). Hydrothermal modifications of granular 
starch with retention of the granular structure: A review. J. of Agri. and Food Chem. 46: 2895-2905.

Jacobs, H., Eerlingen, R.C., Spaepen, H., Grobert, P.J., and Delcour, J.A. (1998). Impact of annealing on the susceptibility of wheat, potato and pea starches to hydrolysis with pancreatin. Carbo. Res. 305: 193-207.

Jane, J.L., Wong, K.S., and McPherson, A.E. (1997). Branch-structure difference in starches of A- and B-type X-ray patterns revealed by their Nägeli dextrins. Carbo. Res. 300: 219-227.

Jayakody, L., and Hoover, R. (2008). Effect of annealing on the molecular structure and physicochemical properties of starches from different botanical origin - A review. Carbo. Poly. 74(3): 691-703.

Jayaprakasha, H.M., Yoon, Y.C., and Brueckner, H. (2000). Critical aspects in adoption of ultra high pressure technology for food processing. Korean J. of Food Sci. and Animal Res. 20: 44-55.

Jeyamkondan, S., Jayas, D.S., and Holley, R.A. (1999). Pulsed electric field processing of foods: a review. J. of Food Pro. 62(9): 1088-1096.

Jiang, F., Du, C., Jiang, W., Wang, L., and Du, S.K. (2020). The preparation, formation, fermentability, and applications of resistant starch. Int. J. of Bio. Macro. 150: 1155-1161.

Jiranuntakulm, W., Puttanlek, C., Rungsardthong, V., Puncha-arnon, S., and Uttapap, D. (2011). Microstructural and physicochemical properties of heat-moisture treated waxy and normal starches. J. of Food Engi. 104: $246-258$.

Jyothi, A.N., Sajeev, M.S., and Sreekumar, J. (2011). Hydrothermal modifications of tropical tuber starches-effect of ANN on the physicochemical, rheological and gelatinization characteristics. Starch/Stärke. 63: 536-549.

Katopo, H., Song, Y., and Jane, J-L. (2002). Effect and mechanism of ultrahigh hydrostatic pressure on the structure and properties of starches. Carbo. Poly. 47: 233-244.

Kim, J-Y., and Huber, K.C. (2013). Heat-moisture treatment under mildly acidic conditions alters potato starch physicochemical properties and digestibility. Carbo. Poly. 98: 1245-1255.

Lan, H., Hoover, R., Jayakody, L., Liu, Q., Donner, E., Baga, M., Asare, E.K., Hucl, P., and Chibbar, R.N. (2008). Impact of annealing on the molecular structure and physicochemical properties of normal, waxy and high amylose bread wheat starches. Food Chem. 111: 663-675.

Lee, C.J., and Moon, T.W. (2015). Structural characteristics of slowly digestible starch and resistant starch isolated from heat-moisture treated waxy potato starch. Carbo. Poly. 125: 200-205.

Lee, C.J., Kim, Y., Choi, S.J., and Moon, T.W. (2012). Slowly digestible starch from heat-moisture treated waxy potato starch: Prepartaion, structural characteristics, and glucose response in mice. Food Chem. 133: 1222-1229.

Lehman, U., and Robin, F. (2007). Slowly digestible starch-its structure and health implications: a review. Trends in Food Sci. and Tech. 18: 346-355.

Li, H., Wang, R., Liu, J., Zhang, Q., Li, G., Shan, Y., and Ding, S. (2020). Effects of heat-moisture and acid treatments on the structural, physicochemical, and in vitro digestibility properties of lily starch. Int. J. of Bio. Macro. 148: 956-968.

Li, N., Wang, L., Zhao, S., Qiao, D., Jia, C., Niu, M., Lin, Q., and Zhang, B. (2020). An insight into starch slowly digestible features enhanced by microwave treatment. Food Hydro. 103: 105690

Li, Q., Wu, Q.Y., Jiang, W., Qian, J.Y., Zhang, L., Wu, M., Rao, S., and Wu, C.S. (2019). Effect of pulsed electric field on structural properties and digestibility of starches with different crystalline type in solid state. Carbo. Poly. 207: 362-370.

Li, S.-L., and Gao, Q.-Y. (2010). Effect of heat-moisture treatment on the formation and properties of resistant starches from mung bean (Phaseolus radiatus) starches. World Academy of Sci., Engi. and Tech. 48: 812-819.

Li, W., Bai, Y., Mousaa, S.A.S., Zhang, Q., and Shen, Q. (2012). Effect of high hydrostatic pressure on physicochemical and structural properties of rice starch. Food Bio. Tech. 5: 2233-2241.

Liu, Y., Selomulyo, V.O., and Zhou, W. (2008). Effect of high pressure on some physicochemical properties of several native starches. J. of Food Engi. 88: 126-136.

Luo, Z., He, X., Fu, X., Luo, F., and Gao, Q. (2006). Effect of microwave radiation on the physicochemical properties of normal maize, waxy maize and amylomaize V starches. Starch/Stärke. 58: 468-474.
Ma, M., Zhang, Y., Chen, X., Li, H., Sui, Z., and Corke, H. (2020). Microwave irradiation differentially affect the physicochemical properties of waxy and non-waxy hull-less barley starch. J. of Cereal Sci. 95: 103072.

Ma, Z., Hu, X., and Boye, J.I. (2020). Research advances on the formation mechanism of resistant starch type III: A review. Cri. Rev. in Food Sci. and Nutri. 60(2): 276-297.

Miao, M., Jiang, B., Cui, S.W., Zhang, T., and Jin, Z. (2015). Slowly digestible starch-A review. Cri. Rev. in Food Sci. and Nutri. 55(12): 1642-1657.

Niba, L.L. (2002). Resistant starch: a potential functional food ingredient. Nutri. and Food Sci. 32(2): 62-67.

Nugent, A.P. (2005). Health properties of resistant starch. British Nutrition Foundation, Nutri. Bulletin. 30: 27-54.

O'Brien and Wang, J.Y. (2008). Susceptibility of annealed starches to hydrolysis by $\alpha$ amylase and glucoamylase. Carbo. Poly. 72: 597-607.

Palav, T., and Seetharaman, K. (2007). Impact of microwave heating on the physico-chemical properties of a starch starch-water model system. Carbo. Poly. 67: 596-604

Perera, A., Meda, V., and Tyler, R.T. (2010). Resistant starch: A review of analytical protocols for determining resistant starch and of factors affecting the resistant starch content of foods. Food Res. Int. 43: 1959-1974.

Perera, C., and Hoover, R. (1998). The relativity of porcine pancreatic alpha-amylase towards native, defatted and heat-moisture treated potato starches before and after hydroxypropylation. Starch/Stärke. 50: 206-213.

Piecyk, M., Drużyńska, B., Ołtarzewska, A., Wołosiak, R., Worobiej, E., and Ostrowska-Ligęza, E. (2018). Effect of hydrothermal modifications on properties and digestibility of grass pea starch. Int. J. of Bio. Macro. 118: 2113-2120.

Punia, S. (2020). Barley starch modifications: Physical, chemical and enzymatic-A review. Int. J. of Bio. Macro. 144: 578-585.

Riaz, M.N. (2000). Introduction to extruders and their principles. In: Riaz, M.N. (Ed.). Extruders in Food Applications.. CRC Press, Boca Raton, FL, pp. 1-21.

Rocha, T.S., Cunha, V.A., Jane, J.L., and Franco, C.M. (2011). Structural characterization of Peruvian carrot (Arracacia xanthorrhiza) starch and the effect of annealing on its semicrystalline structure. J. of Agri. and Food Chem. 59(8): 4208-4216.

Rocha, T.S., Gelizardo, S.G., Jane, J.-L., and Franco, C.M.L. (2012). Effect of annealing on the semicrystalline structure of normal and waxy maize starches. Food Hydro. 29(1): 93-99.

Roebuck, B.D., Goldblith, S.A., and Westphal, W.B. (1972). Dielectric properties of carbohydrate-water mixtures at microwaves frequencies. J. of Food Sci. 37: 199-204.

Sajilata, M.G., Singhal, R.S., and Kulkarni, P.R. (2006). Resistant starch-a review. Comp. Rev. Food Sci. Food Safety. 5(1): 1-17.

Samarakoon, E.R.J., Waduge, R., Liu, Q., Shahidi, F., and Banoub, J.H. (2020). Impact of annealing on the hierarchical structure and physicochemical properties of waxy starches of different botanical origins. Food Chem. 303: 125344.

San, Q., Han, Z., Wang, L., and Xiong, L. (2014). Physicochemical differences between sorghum starch and sorghum flour modified by heatmoisture treatment. Food Chem. 145: 756-764.

Sankhon, A., Amadou, I., Yao, W., Wang, H., Qian, H., and Mlyuka, E. (2014). Effect of different heat-moisture treatments on the physicochemical properties of African locust bean (Parkia biglobosa) starches. J. of Agri. Sci. and Tech. 16: 331-342.

Sharma, S., Singh, N., and Singh, B. (2015). Effect of extrusion on morphology, structural, functional properties and in vitro digestibility of corn, field pea and kidney bean starches. Starch/Stärke. 67: 721-728.

Shen, X., Shang, W., Strappe, P., Chen, L., Li, X., Zhou, Z., and Blanchard, C. (2018). Manipulation of the internal structure of high amylose maize starch by high pressure treatment and its diverse influence on digestion. Food Hydro. 77: 40-48.

Shrestha, A.K., Blazek, J., Flanagan, B.M., Dhital, S., Larroquec, O., Morellc, M.K., Gilbertb, E.P., and Gidley, M.J. (2015). Molecular, mesoscopic and microscopic structure evolution during amylase digestion of extruded maize and high amylose maize starches. Carbo. Poly. 118: 224-234.

Shrestha, A.K., Ng, C.N., Lopez-Rubio, A., Blazek, J., Gilbert, E.P., and Gidley, M.J. (2010). Enzyme resistance and structural organization in ex- 
truded high amylose maize starch. Carbo. Poly. 80: 699-710.

Simsek, S., Ovando-Martinez, M., Whitney, K., and Bello-Perez, L. (2012) Effect of acetylation, oxidation, and annealing on physicochemical properties of bean starch. Food Chem. 134: 1796-1803.

Singh, J., Dartois, A., and Kaur, L. (2010). Starch digestibility in food matrix: a review. Trends in Food Sci. and Tech. 21: 168-180.

Singh, S., Gamlath, S., and Wakeling, L. (2007). Nutritional aspects of food extrusion: a review. Int. J. of Food Sci. and Tech. 42: 916-929.

Son Trinh, K., Joo Lee, C., Jun Choi, S., and Wha Moon, T. (2012). Hydrothermal Treatment of Water Yam Starch in a Non-granular State: Slowly Digestible Starch Content and Structural Characteristics. J. of Food Sci. 77(6): C574-C582.

Song, H.Y., Lee, S.Y., Choi, S.J., Kim, M.K., Kim, J.S., Han, G.J., and Moon, T.W. (2014). Digestibility and physicochemical properties of granular sweet potato starch as affected by annealing. Food Sci. Biotech. 23 23-31.

Srikaeo, K. (2016). Starch: Introduction and structure-property relationship. In: Visakh, P.M., and Yu, L. (Ed.). Starch-based Blends, composites and nanocomposites. Royal Society of Chemistry, London, UK, pp. 17-59.

Stute, R., Klingler, R.W., Boguslawski, S., Eshtiaghi, M.N., and Knorr, D. (1996). Effects of high pressures treatment on starches. Starch/ Stärke. 48: 399-408.

Su, C., Saleh, A.S., Zhang, B., Zhao, K., Ge, X., Zhang, Q., and Li, W. (2020). Changes in structural, physicochemical, and digestive properties of normal and waxy wheat starch during repeated and continuous annealing. Carbo. Poly. 247: 116675

Tahir, R., Ellis, P.R., Bogracheva, T.Y., Meares-Taylor, C., and Butterworth, P.J. (2010). Study of the structure and properties of native and hydrothermally processed wild-type, lam and $r$ variant pea starches that affect amylolysis of these starches. Biomacromolecules. 12(1): 123-133.

Thostenson, E.T., and Chou, T.W. (1999). Microwave processing: fundamentals and applications. Composites: Part A. 30: 1055-1071.

Tian, Y., Li, D., Zhao, J., Xu, X., and Jin, Z. (2014). Effect of high hydrostatic pressure (HHP) on slowly digestible properties of rice starches. Food Chem. 152: 225-229.

Trung, P.T.B., Ngoc, L.B.B., Hoa, P.N., Tien, N.N.T., and Van Hung, P. (2017) Impact of heat-moisture and annealing treatments on physicochemical properties and digestibility of starches from different colored sweet potato varieties. Int. J. of Bio. Macro. 105: 1071-1078.

Uthumporn, U., Zaidul, I.S., and Karim, A.A. (2010). Hydrolysis of granular starch at sub-gelatinization temperature using a mixture of amylolytic enzymes. Food and Bioproducts Pro. 88(1): 47-54.

Varatharajan, V., Hoover, R., Li, J., Vasanthan, T., Nantanga, K.K.M., Seetharaman, K., Liu, Q., Donner, E., Jaiswal, S., and Chibbar, R.N. (2011). Impact of structural changes due to heat-moisture treatment at different temperatures on the susceptibility of normal and waxy potato starches towards hydrolysis by porcine pancreatic alpha amylase. Food Res. Int. 44: 2594-2606.

Varatharajan, V., Hoover, R., Liu, Q., and Seetharaman, K. (2010). The impact of heat moisture treatment on the molecular structure and physicochemical properties of normal and waxy potato starches. Carbo. Poly. 81: 466-475.

Vieira, F.C., and Sarmento, S.B.S. (2008). Heat-moisture treatment and enzymatic digestibility of Peruvian carrot, sweet potato and ginger starches. Starch/Stärke. 60: 223-232.

Waduge, R.N., Hoover, R., Vasanthan, T., Gao, J., and Li, J. (2006). Effect of annealing on the structure and physicochemical properties of barley starches of varying amylose content. Food Res. Int. 39: 59-77.

Wang, H., Zhang, B., Chen, L., and Li, X. (2016). Understanding the structure and digestibility of heat-moisture treated starch. Int. J. of Bio. Macro. 88: 1-8.

Wang, J., Zhu, H., Li, S., Wang, S., Wang, S., and Copeland, L. (2017). Insights into structure and function of high pressure-modified starches with different crystalline polymorphs. Int. J. of Bio. Macro. 102: 414-424.

Wang, Q., Li, L., and Zheng, X. (2020). Recent advances in heat-moisture modified cereal starch: Structure, functionality and its applications in starchy food systems. Food Chem. 128700.

Wang, S., Jin, F., and Yu, J. (2013). Pea starch annealing: new insights. Food Bioprocess Tech. 6: 3564-3575

Wang, S., Wang, J., Yu, J., and Wang, S. (2014). A comparative study of an- nealing of waxy, normal and high-amylose maize starches: The role of amylose molecule. Food Chem. 164: 332-338.

Watcharatewinkul, Y., Uttapap, D., Puttanlek, C., and Rungsardthong, V. (2010). Enzyme digestibility and acid/shear stability of heat-moisture treated canna starch. Starch/Stärke. 62: 205-216.

Wolf, B. (2010). Polysaccharide functionality through extrusion process ing. Cur. Opi. in Colloid and Interface Sci. 15: 50-54.

Wu, C., Wu, Q.Y., Wu, M., Jiang, W., Qian, J.Y., Rao, S.Q., Zhang, L., Li, Q., and Zhang, C. (2019). Effect of pulsed electric field on properties and multi-scale structure of japonica rice starch. LWT. 116: 108515.

Yan, X., Wu, Z.Z., Li, M.Y., Yin, F., Ren, K.X., and Tao, H. (2019). The combined effects of extrusion and heat-moisture treatment on the physicochemical properties and digestibility of corn starch. Int. J. of Bio. Macro. 134: 1108-1112.

Ye, J., Liu, C., Luo, S., Hu, X., and McClements, D.J. (2018). Modification of the digestibility of extruded rice starch by enzyme treatment ( $\beta$-amylolysis): An in vitro study. Food Res. Int. 111: 590-596.

Zavareze, E.d.R., and Dias, A.R.G. (2011). Impact of heat-moisture treatment and annealing in starches: a review. Carbo. Poly. 83: 317-28.

Zavareze, E.d.R., El Halal, S.L.M., de los Santos, D.G., Helbig, E., Pereira, J.M. and Dias, A.R.G. (2012). Resistant starch and thermal, morphological and textural properties of heat-moisture treated rice starches with high-, medium- and low-amylose content. Starch/Stärke. 64: 45-54.

Zavareze, E.d.R., Storck, C.R., de Castro, L.A.S., Schirmer, M.A., and Dias, A.R.G. (2010). Effect of heat-moisture treatment on rice starch of varying amylose content. Food Chem. 121: 359-365.

Zeng, F., Gao, Q., Han, Z., Zeng, X., and Yu, S. (2016). Structural properties and digestibility of pulsed electric field treated waxy rice starch. Food Chem. 194: 1313-1319.

Zeng, F., Ma, F., Kong, F., Gao, Q., and Yu, S. (2015). Physicochemical prop erties and digestibility of hydrothermally treated waxy rice starch. Food Chem. 172: 92-98.

Zhang, B., Dhital, S., and Gideley, M.J. (2013). Synergistic and antagonistic effects of $\alpha$-amylase and amyloglucosidase on starch digestion. Biomacromolecules. 14: 1945-1954.

Zhang, B., Zhao, K., Su, C., Gong, B., Ge, X., Zhang, Q., and Li, W. (2020) Comparing the multi-scale structure, physicochemical properties and digestibility of wheat A-and B-starch with repeated versus continuous heat-moisture treatment. Int. J. of Bio. Macro. 163: 519-528.

Zhang, C., Lim, S.T., and Chung, H.J. (2019). Physical modification of potato starch using mild heating and freezing with minor addition of gums. Food Hydro. 94: 294-303.

Zhang, G., and Hamaker, B.R. (2009). Slowly digestible starch: concept, mechanism, and proposed extended glycemic index. Cri. Rev. in Food Sci.and Nutri. 49: 852-867.

Zhang, G., Ao, Z., and Hamaker, B.R. (2006a). Slow digestion property of native cereal starches. Biomacromolecules. 7: 3252-3258.

Zhang, G., Venkatachalam, M., and Hamaker, B.R. (2006b). Structural basis for the slow digestion property of native cereal starch. Biomacromolecules. 7: 3259-3266.

Zhang, J., Chen, F., Liu, F., and Wang, Z.-W. (2010). Study on structural changes of microwave heat-moisture treated resistant Canna edulis Ker starch during digestion in vitro. Food Hydro. 24: 27-34.

Zhang, J., Wang, Z., and Yang, J. (2010). Physicochemical properties of Canna edulis Ker starch on heat-moisture treatment. Int. J. of Food Pro. 13: 1266-1279.

Zhang, J., Wang, Z.W., and Shi, X.M. (2009). Effect of microwave heat/ moisture treatment on physicochemical properties of Canna edulis Ker starch. J. of the Sci. of Food and Agri. 89: 653-664.

Zhong, Y., Liang, W., Pu, H., Blennow, A., Liu, X., and Guo, D. (2019). Shorttime microwave treatment affects the multi-scale structure and digestive properties of high-amylose maize starch. Int. J. of Bio. Macro. 137: 870-877.

Zhong, Y., Xiang, X., Zhao, J., Wang, X., Chen, R., Xu, J., Luo, S., Wu, J., and Liu, C. (2020). Microwave pretreatment promotes the annealing modification of rice starch. Food Chem. 304: 125432

Zou, J., Xu, M., Wang, R., and Li, W. (2019). Structural and physicochemical properties of mung bean starch as affected by repeated and continuous annealing and their in vitro digestibility. Int. J. of Food Pro. 22(1): 898-910. 